\title{
Synergies of sector coupling and transmission reinforcement in a cost-optimised, highly renewable European energy system
}

\author{
T. Brown ${ }^{\mathrm{a}, \mathrm{b}, *}$, D. Schlachtberger ${ }^{\mathrm{b}}$, A. Kies ${ }^{\mathrm{b}}$, S. Schramm ${ }^{\mathrm{b}}$, M. Greiner $^{\mathrm{c}}$ \\ ${ }^{a}$ Institute for Automation and Applied Informatics, Karlsruhe Institute of Technology, Hermann-von-Helmholtz-Platz 1, 76344 Eggenstein-Leopoldshafen, \\ Germany \\ ${ }^{b}$ Frankfurt Institute for Advanced Studies, Ruth-Moufang-Straße 1, 60438 Frankfurt am Main, Germany \\ ${ }^{c}$ Department of Engineering, Aarhus University, 8000 Aarhus C, Denmark
}

\section{$\infty$ Abstract}

There are two competing concepts in the literature for the integration of high shares of renewable energy: the coupling of electricity to other energy sectors, such as transport and heating, and the reinforcement of continent-wide transmission networks. In this paper both cross-sector and cross-border integration are considered in the model PyPSA-Eur-Sec-30, the first open, spatiallyresolved, temporally-resolved and sector-coupled energy model of Europe. Using a simplified network with one node per country, the cost-optimal system is calculated for a 95\% reduction in carbon dioxide emissions compared to 1990, incorporating electricity, transport and heat demand. Flexibility from battery electric vehicles (BEV), power-to-gas units (P2G) and long-term thermal energy storage (LTES) make a significant contribution to the smoothing of variability from wind and solar and to the reduction of total system costs. The cost-minimising integration of BEV pairs well with the daily variations of solar power, while P2G and LTES balance the synoptic and seasonal variations of demand and renewables. In all scenarios, an expansion of cross-border transmission reduces system costs, but the more tightly the energy sectors are coupled, the weaker the benefit of transmission reinforcement becomes.

Keywords: energy system design, large-scale integration of renewable power generation, sector coupling, power transmission, $\mathrm{CO}_{2}$ emission reduction targets

\section{Introduction}

It has been established in many studies that the integration of high shares of renewable energy in the European electricity sector is both technically feasible and affordable [1-8] (see also the review [9]). Typically, these studies show that the most costeffective solutions are dominated by wind generation and require the expansion of a pan-continental transmission network, which enables the exploitation of the best renewable production sites and smooths out the variations from weather systems on the synoptic scale $(\sim 600-1000 \mathrm{~km})$ as they pass over the continent. Without an expansion of the transmission network, more expensive electricity storage solutions are needed to balance the variability of renewables in time [10-14].

However, focussing on the electricity sector means not only neglecting the significant greenhouse gas emissions from other energy demand sectors, such as heating and transport, but also ignoring important sources of flexibility in these sectors. In what some authors term 'smart energy systems' [15], demand from, for example, battery electric vehicles or intelligent heating systems can be brought forward or delayed to reduce system costs, and low-cost long-term storage can be provided either chemically, using power-to-gas units to produce synthetic

\footnotetext{
${ }^{*}$ Corresponding author

Email address: tom. brown@kit. edu (T. Brown)
}

fuels such as hydrogen and methane (so called 'electrofuels'), or thermally [16]. Long-term storage can smooth out both the seasonal variations of renewables and the synoptic variations ( 3-10 days in the time dimension).

Modelling all energy sectors in high spatial and temporal detail is computationally demanding. In order to maintain computational tractability, previous sector coupling studies have either focused on just a few demand sectors, or sacrificed spatial or temporal resolution.

Studies of a few sectors have either considered just electricity and heat, electricity and transport, or electricity and gas. For example, in $[17,18]$ the possibility of using excess renewable electricity in the heating sector was considered, but no requirements were set to defossilise all heating, or to couple to other demand sectors. In another set of studies, a simplified investment and dispatch scheme was used for a one-node-per-country model of Europe to study electricity-heat coupling [19]. Interactions between the electricity sector and transport were studied for electric vehicles in [20-22] and including fuel cell electric vehicles in $[23,24]$. More general coupling of electricity to gas for use in either heating or transport was considered in [25, 26].

Studies that include multiple sectors, often encompassing all energy usage, but that sacrifice spatial resolution have typically either considered single countries (e.g. Germany [27-30], Denmark [31-33], Ireland [34, 35]) or considered the whole continent of Europe without any spatial differentiation [36] so that 
international network bottlenecks are not visible. In one study two countries, Denmark to represent Northern Europe and Italy to represent Southern Europe, were coupled to compare crossborder with cross-sectoral coupling [37]; while both strategies demonstrated benefits, cross-sectoral coupling gave the best performance.

Another option to reduce computation times is to include multiple sectors and/or multiple countries, but reduce the number of representative demand and weather situations to several typical days [38-42]. A lower intra-annual resolution allows optimisation of investment paths over multiple decades, but does not allow enough resolution to assess the variability and flexibility requirements for high shares of wind and solar power $[43,44]$.

In this paper both sector coupling and international grid integration are considered in the model PyPSA-Eur-Sec-30, the first open, hourly, country-resolved, sector-coupled investment model of the European energy system. Generation, storage and transmission investment are optimized so that demand for electricity, space and water heating, and land transport is met under the condition that carbon dioxide emissions are reduced by $95 \%$ compared to 1990 levels, in line with European Union targets [45]. ${ }^{1}$ It is assumed that both heating and transport can be electrified, using for example heat pumps to meet heating demand and electric vehicles for transport, both of which leverage significantly higher efficiencies than their fossil-fuelled counterparts.

The novelty in the model presented here is that the combination of pan-continental integration and sector coupling in one model with hourly time resolution over a full year allows a full consideration of which competing concept is more costeffective: smoothing of renewable fluctuations in space with networks or in time with demand-side management and lowcost long-term storage. Compared to electricity-only models it has heating and transport demand for more energy coverage and enhanced flexibility; compared to the sector-coupled models with low spatial resolution, a full consideration of crossborder exchange is possible; compared to the models with low temporal resolution, the model can distinguish between flexibility options at different time scales, and thus account for all the cross-correlations of weather patterns over time.

The model is further distinguished by being fully open, in the sense that all the input data, processing code and output data is freely available online [47, 48] and may be re-used by anyone, thereby enhancing transparency and reproduceability [49, 50].

In Section 2 the model framework is described, before the input data which defines the model instance PyPSA-Eur-Sec30 is documented in Section 3. In Section 4 the results are presented and analysed; in Section 5 the results are compared to the literature and the limitations of the study are discussed. Conclusions are drawn in Section 6.

\footnotetext{
${ }^{1} 1990$ is the standard reference year both for the European Union targets and for the Kyoto Protocol [46].
}

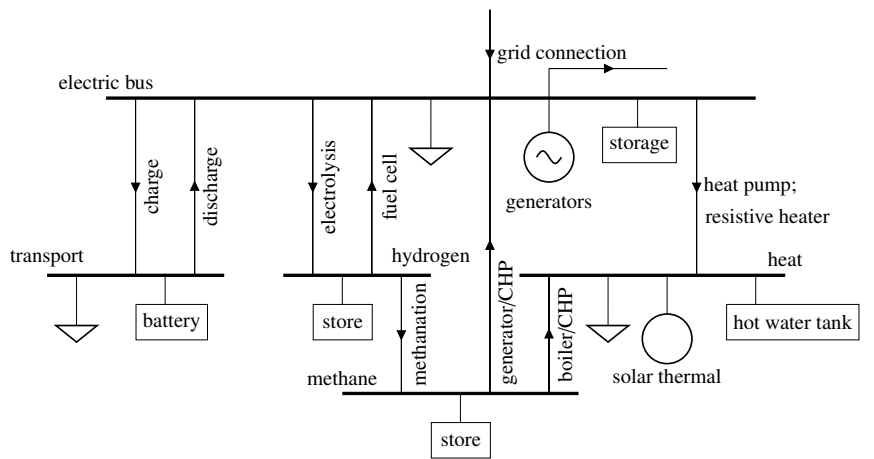

Figure 1: Energy flow at a single node. In this model, a node represents a whole European country. Within each node there is a bus (thick horizontal line) for each energy carrier (electric, transport, heat, hydrogen and methane), to which different loads (triangles), energy sources (circles), storage units (rectangles) and converters (lines connecting buses) are attached.

\section{Model}

In this section the equations of the model are described, as implemented in the modelling framework PyPSA [51].

The model uses linear optimisation to minimise annual operational and investment costs subject to technical and physical constraints, assuming perfect competition and perfect foresight. Market prices are derived in the model that guarantee that each asset owner recovers their costs from the market.

Each of the 30 European countries considered in the model is aggregated to a single node, each of which consists of individual 'buses' (vertices to which energy assets are attached) for electricity, heat, transport, hydrogen and methane. The electric buses are connected together with transmission represented by High Voltage Direct Current (HVDC) lines; the buses of the different sectors are connected within a node with energy converters as shown in Figure 1.

Generator capacities (for onshore wind, offshore wind, solar photovoltaic (PV) and natural gas), storage capacities (for batteries, hydrogen storage and conversion, methanisation and hot water tanks), heating capacities (for heat pumps, resistive heaters, gas boilers, combined heat and power (CHP) plants and solar thermal collector units) and transmission capacities are all subject to optimisation, as well as the operational dispatch of each unit in each hour. Demand curves for the different sectors, the ratio of district heating to decentralised heating, the number of electric vehicles, methane storage and hydroelectricity capacities (for reservoir and run-of-river generators and pumped hydro storage) are exogenous to the model and not optimised.

Investment and operation are optimised over a full historical year of hourly weather and demand data assuming perfect foresight, with 2011 chosen as the representative year. In [52], 2011 was found to be ideal for scenario definition because of its average wind conditions, slightly lower heating demand and higher PV feed-in than average that can represent the (small) effects of global warming expected by 2050, and the fact that it still contains a very cold spell for dimensioning the supply of maximum heating demand. While it would be desirable to model over multiple weather years in order to capture inter- 
annual variability and more extreme weather events, as well as to model forecast uncertainty, this is currently not computationally feasible because of the large number of variables. Results from other simulations for multiple years are discussed in Section 5.3.

If buses are labelled by $n$, generation and storage technologies at the bus by $s$, hour of the year by $t$ and bus connectors by $\ell$ (which includes transmission lines and energy converters such as heat pumps and battery chargers), then the total annual system cost consists of fixed annualised costs $c_{n, s}$ for generation and storage power capacity $G_{n, s}$, fixed annualised costs $\hat{c}_{n, s}$ for storage energy capacity $E_{n, s}$, fixed annualised costs $c_{\ell}$ for bus connectors $F_{\ell}$, variable costs $o_{n, s, t}$ for generation and storage dispatch $g_{n, s, t}$, as well as variable costs $o_{\ell, t}$ for power flow $f_{\ell, t}$ through connectors. The objective function is then

$$
\begin{gathered}
\min _{\substack{G_{n, s}, E_{n, s}, F_{\ell} \\
g_{n, s, t} f_{\ell, t}}}\left[\sum_{n, s} c_{n, s} \cdot G_{n, s}+\sum_{n, s} \hat{c}_{n, s} \cdot E_{n, s}+\sum_{\ell} c_{\ell} \cdot F_{\ell}\right. \\
\left.+\sum_{n, s, t} o_{n, s, t} \cdot g_{n, s, t}+\sum_{\ell, t} o_{\ell, t} \cdot f_{\ell, t}\right]
\end{gathered}
$$

The inelastic energy demand $d_{n, t}$ at each bus $n$ must be met at each time $t$ by either local generators and storage or by the flow $f_{\ell, t}$ from a connector $\ell$

$$
\sum_{s} g_{n, s, t}+\sum_{\ell} \alpha_{\ell, n, t} \cdot f_{\ell, t}=d_{n, t} \quad \leftrightarrow \quad \lambda_{n, t} \quad \forall n, t
$$

where $\alpha_{\ell, n, t}=-1$ if $\ell$ starts at $n$ and $\alpha_{\ell, n, t}=\eta_{\ell, t}$ if $\ell$ ends at n. $\eta_{\ell, t}$ is a factor for the efficiency of the energy conversion in $\ell$; it can be time-dependent for efficiency that, for example, depends on the outside temperature, like for a heat pump. The Karush-Kuhn-Tucker (KKT)/Lagrange multiplier $\lambda_{n, t}$ represents the market price of the energy carrier at this bus in this hour.

The dispatch $g_{n, s, t}$ of each generator and storage unit is constrained by its capacity $G_{n, s}$ and time-dependent availabilities $\bar{g}_{n, s, t}$ and $\underline{g}_{n, s, t}$, which are given per unit of the capacity $G_{n, s}$ :

$$
\underline{g}_{n, s, t} \cdot G_{n, s} \leq g_{n, s, t} \leq \bar{g}_{n, s, t} \cdot G_{n, s} \quad \forall n, s, t
$$

For flexible conventional generators the availabilities are constant $\underline{g}_{n, s, t}=0$ and $\bar{g}_{n, s, t}=1$. For variable renewable generators such as wind and solar, the time-varying $\bar{g}_{n, s, t}$ represents the weather-dependent power availability, and since curtailment is allowed, $\underline{g}_{n, s, t}=0$. For battery storage $\underline{g}_{n, s, t}=-1$ and $\bar{g}_{n, s, t}=1$.

The power capacity $G_{n, s}$ is optimised within minimum $\underline{G}_{n, s}$ and maximum $\bar{G}_{n, s}$ installable potentials:

$$
\underline{G}_{n, s} \leq G_{n, s} \leq \bar{G}_{n, s} \quad \forall n, s
$$

The energy levels $e_{n, s, t}$ of all storage units have to be consistent with the dispatch in all hours and are limited by the storage energy capacity $E_{n, s}$

$$
\begin{aligned}
e_{n, s, t}= & \eta_{0} \cdot e_{n, s, t-1}-\eta_{1}\left[g_{n, s, t}\right]^{-}-\eta_{2}^{-1}\left[g_{n, s, t}\right]^{+} \\
& +g_{n, s, t \text {,inflow }}-g_{n, s, t, \text { spillage }} \\
\underline{e}_{n, s, t} \cdot E_{n, s} \leq & e_{n, s, t} \leq \bar{e}_{n, s, t} \cdot E_{n, s} \quad \forall n, s, t
\end{aligned}
$$

Positive and negative parts of a value are denoted as $[\cdot]^{+/-}=$ $\max / \min (\cdot, 0)$. The storage units can have a standing leakage loss $\eta_{0}$, a charging efficiency $\eta_{1}$, a discharging efficiency $\eta_{2}$, inflow (e.g. river inflow in a reservoir) and spillage. The energy level can be set to be cyclic, i.e. $e_{n, s, t=0}=e_{n, s, t=T}$. The energy levels of the store can also be restricted by time series $\underline{e}_{n, s, t}, \bar{e}_{n, s, t}$ given per unit of the energy capacity $E_{n, s}$. This is used to model the demand-side management of battery electric vehicles. The storage energy capacity $E_{n, s}$ can be optimised independently of the storage power capacity $G_{n, s}$, within installable potentials.

Flows on bus connectors are constrained by their capacities $F_{\ell}$ and time-dependent per unit availabilities $\underline{f}_{\ell, t}, \bar{f}_{\ell, t}$

$$
f_{\ell, t} \cdot F_{\ell} \leq f_{\ell, t} \leq \bar{f}_{\ell, t} \cdot F_{\ell} \quad \forall \ell, t
$$

For the HVDC links between electricity buses in different countries $f_{\ell, t}=-1$ and $\bar{f}_{\ell, t}=1$; for a resistive heater from an electricity bus to a heat bus in the same country the connector is unidirectional $f_{\ell, t}=0$ and $\bar{f}_{\ell, t}=1$ since the heater cannot convert heat back into electricity; the availabilities become time dependent for the charging of electric vehicles.

In order to investigate the merits of international transmission, the sum of transmission line capacities multiplied by their lengths $l_{\ell}$ can be restricted by a line volume cap $\mathrm{CAP}_{L V}$, which is then varied in different simulations:

$$
\sum_{\ell \in \mathrm{HVDC}} l_{\ell} \cdot F_{\ell} \leq \mathrm{CAP}_{L V}
$$

Line capacities are weighted by their lengths because the length increases both the cost and potential public acceptance concerns for overhead transmission lines.

$\mathrm{CO}_{2}$ emissions are also limited by a cap $\mathrm{CAP}_{\mathrm{CO} 2}$, implemented using the specific emissions $\varepsilon_{s}$ in $\mathrm{CO}_{2}$-tonne-per$\mathrm{MWh}_{\mathrm{th}}$ of the fuel $s$, the efficiency $\eta_{n, s}$ and dispatch $g_{n, s, t}$ for generators, and the difference in energy level for non-cyclic stores (relevant for methane, which is depleted during the year):

$$
\sum_{n, s, t} \varepsilon_{S} \frac{g_{n, s, t}}{\eta_{n, s}}+\sum_{n, s} \varepsilon_{s}\left(e_{n, s, t=0}-e_{n, s, t=T}\right) \leq \mathrm{CAP}_{C O 2} \quad \leftrightarrow \quad \mu_{C O 2}
$$

The KKT multiplier $\mu_{\mathrm{CO} 2}$ indicates the carbon dioxide price necessary to obtain this reduction in an open market.

The model was implemented in the free software energy modelling framework 'Python for Power System Analysis' (PyPSA) [51]. Each run took between 3 and 5 hours, depending on the model parameters, using the commercial linear programming solver Gurobi [53]. Gurobi was configured to use two threads on an AMD Opteron 6274 machine with 64 GB of RAM and $1.4 \mathrm{GHz}$ processing speed per virtual core.

\section{Input Data}

In this section the input data for the model instance PyPSAEur-Sec-30 are described. Table 1 summarises the different investments the model can make, their costs, efficiencies and other parameters. All energies and conversion efficiencies for methane and hydrogen are given in terms of the higher heating value (HHV). For power plants, all capacities refer to net generation capacities. 
Table 1: Input parameters based on 2030 value estimates

\begin{tabular}{|c|c|c|c|c|c|c|}
\hline Technology & $\begin{array}{r}\text { Overnight } \\
\text { Cost [€] }\end{array}$ & Unit & $\begin{array}{l}\mathrm{FOM}^{\mathrm{a}} \\
{[\% / \mathrm{a}]}\end{array}$ & $\begin{array}{r}\text { Lifetime } \\
{[\mathrm{a}]}\end{array}$ & Efficiency & Source \\
\hline Wind onshore & 1182 & $\mathrm{~kW}_{\mathrm{el}}$ & 3 & 25 & 1 & {$[54]$} \\
\hline Wind offshore & 2506 & $\mathrm{~kW}_{\mathrm{el}}$ & 3 & 25 & 1 & [54] \\
\hline Solar PV rooftop & 725 & $\mathrm{~kW}_{\mathrm{el}}$ & 2 & 25 & 1 & [55] \\
\hline Solar PV utility & 425 & $\mathrm{~kW}_{\mathrm{el}}$ & 3 & 25 & 1 & {$[55]$} \\
\hline Open cycle gas turbine (OCGT) & 400 & $\mathrm{~kW}_{\mathrm{el}}$ & 4 & 30 & 0.39 & {$[54,56]$} \\
\hline Pumped hydro storage $\mathrm{e}^{\mathrm{b}}$ & 2000 & $\mathrm{~kW}_{\mathrm{el}}$ & 1 & 80 & $0.87 \cdot 0.87$ & [54] \\
\hline Hydro reservoir ${ }^{\mathrm{b}}$ & 2000 & $\mathrm{~kW}_{\mathrm{el}}$ & 1 & 80 & 0.9 & [54] \\
\hline Run-of-river ${ }^{b}$ & 3000 & $\mathrm{~kW}_{\mathrm{el}}$ & 2 & 80 & 0.9 & [54] \\
\hline Battery inverter & 310 & $\mathrm{~kW}_{\mathrm{el}}$ & 3 & 20 & $0.9 \cdot 0.9$ & {$[57]$} \\
\hline Battery storage & 144.6 & $\mathrm{kWh}$ & 0 & 15 & 1 & [57] \\
\hline Hydrogen electrolysis & 350 & $\mathrm{~kW}_{\mathrm{el}}$ & 4 & 18 & 0.8 & [58] \\
\hline Hydrogen fuel cell ${ }^{\mathrm{c}}$ & 339 & $\mathrm{~kW}_{\mathrm{el}}$ & 3 & 20 & 0.58 & {$[57,59]$} \\
\hline Hydrogen storage $^{\mathrm{d}}$ & 8.4 & $\mathrm{kWh}$ & 0 & 20 & 1 & [57] \\
\hline Methanation ${ }^{\mathrm{e}}$ & 750 & $\mathrm{~kW}_{\mathrm{H}_{2}}$ & 2.5 & 25 & 0.8 & [58] \\
\hline $\mathrm{CO}_{2}$ direct air capture $(\mathrm{DAC})^{\mathrm{e}}$ & 228 & $\mathrm{tCO}_{2} / \mathrm{a}$ & 4 & 30 & see text & {$[60]$} \\
\hline Methanation + DAC ${ }^{\mathrm{e}}$ & 1000 & $\mathrm{~kW}_{\mathrm{H}_{2}}$ & 3 & 25 & 0.6 & {$[58,60]$} \\
\hline Air-sourced heat pump decentral & 1050 & $\mathrm{~kW}_{\text {th }}$ & 3.5 & 20 & variable & {$[27,58]$} \\
\hline Air-sourced heat pump central & 700 & $\mathrm{~kW}_{\mathrm{th}}$ & 3.5 & 20 & variable & {$[58]$} \\
\hline Ground-sourced heat pump decentral & 1400 & $\mathrm{~kW}_{\mathrm{th}}$ & 3.5 & 20 & variable & [58] \\
\hline Resistive heater & 100 & $\mathrm{~kW}_{\text {th }}$ & 2 & 20 & 0.9 & {$[61]$} \\
\hline Gas condensing boiler decentral & 175 & $\mathrm{~kW}_{\mathrm{th}}$ & 2 & 20 & 0.9 & [58] \\
\hline Gas condensing boiler central & 63 & $\mathrm{~kW}_{\text {th }}$ & 1 & 22 & 0.9 & [58] \\
\hline Combined heat and power (CHP) central & 600 & $\mathrm{~kW}_{\mathrm{th}}$ & 3 & 25 & see text & {$[27]$} \\
\hline Solar thermal collector decentral & 270 & $\mathrm{~m}^{2}$ & 1.3 & 20 & variable & [27] \\
\hline Solar thermal collector central & 140 & $\mathrm{~m}^{2}$ & 1.4 & 20 & variable & [27] \\
\hline Hot water tank decentral & 860 & $\mathrm{~m}^{3}$ & 1 & 20 & $\tau=3$ days & {$[27,29]$} \\
\hline Hot water tank central & 30 & $\mathrm{~m}^{3}$ & 1 & 40 & $\tau=180$ days & {$[27,29]$} \\
\hline Hot water tank (dis)charging & 0 & & & & $0.9 \cdot 0.9$ & [27] \\
\hline High-density district heating network ${ }^{\mathrm{f}}$ & 220 & $\mathrm{~kW}_{\mathrm{th}}$ & 1 & 40 & 1 & [29] \\
\hline Gas distribution network ${ }^{\mathrm{f}}$ & 387 & $\mathrm{~kW}_{\mathrm{th}}$ & 2 & 40 & 1 & based on [62] \\
\hline Building retrofitting $^{f}$ & see text & & 1 & 50 & 1 & {$[27,58]$} \\
\hline HVDC transmission line & 400 & MWkm & 2 & 40 & 1 & [11] \\
\hline HVDC converter pair & 150 & $\mathrm{~kW}$ & 2 & 40 & 1 & [11] \\
\hline
\end{tabular}

${ }^{a}$ Fixed Operation and Maintenance (FOM) costs are give as a percentage of the overnight cost per year.

${ }^{\mathrm{b}}$ Hydroelectric facilities are not expanded in this model and are considered to be fully amortized.

c The fuel cell technology is solid oxide, with partial (30\%) replacement after 10 years, following [59]. The more conservative estimate of efficiency has been taken, in line with other sources [56].

${ }^{\mathrm{d}}$ Hydrogen storage is in overground steel tanks following [57]. The usage of existing underground caverns to store hydrogen could be more than 10 times cheaper [63,64], but a study of cavern potentials across Europe was not within the scope of this study.

e Investments in methanation and DAC are not allowed independently, only together as 'Methanation+DAC', see text.

$\mathrm{f}$ The costs for distribution infrastructure and building retrofitting are approximate (see text) and they are therefore not optimised or included in the presented total system costs, but calculated retrospectively and analysed in the text. 


\subsection{Countries and network}

Following [13], there is one node in the model for each country. The 30 countries consist of those in the major synchronous zones of the European Network of Transmission System Operators for Electricity (ENTSO-E), which includes the 28 European Union member states as of 2018 minus Cyprus and Malta, plus Bosnia and Herzegovina, Norway, Serbia and Switzerland. The nodes are connected with a network based on existing and planned transmission line interconnections between countries. The full network model was presented and validated in [65].

\subsection{Electricity demand}

Hourly demand profiles are constructed that include current electricity consumption and the electrification of fossil-fueled cooking, but that exclude electricity consumption from space and water heating; demand curves for transport and heating are considered separately in Sections 3.4 and 3.6 respectively. This allows the model to decide independently how to meet demand from the different sectors.

The hourly electricity demand profiles for 2011 are based on those from the Open Power System Data project [66], which has conveniently repackaged and unified data from the European Network of Transmission System Operators for Electricity (ENTSO-E) [67]. From these time series the time series for space and water heating demand currently met by electricity in each country is subtracted and added to the heating profiles (see Section 3.6). The remaining electricity time series are then scaled up linearly to account for additional demand from the electrification of fossil-fueled cooking demand in each country. These changes result in a reduction of the original yearly electricity demand for the 30-node model from $3153 \mathrm{TWh}_{\mathrm{el}} / \mathrm{a}$ to $2970 \mathrm{TWh}_{\mathrm{el}} / \mathrm{a}$.

\subsection{Electricity supply}

The model for electricity generation and storage is fully documented in [13], so only a summary is provided here; differences with the model in [13] are listed at the end of this subsection. Electricity can be generated by solar photovoltaics, wind onshore, wind offshore, hydro reservoirs, run-of-river plants, open cycle gas turbines and combined heat and power units.

The potential generation time series for wind generators are computed with the Aarhus University renewable energy atlas, described and validated in [68], based on hourly reanalysis wind data from 2011 with a spatial resolution of $40 \times 40 \mathrm{~km}^{2}$ [69]. The time series for solar PV in 2011 are taken from the Renewables.ninja project, described and validated in [70], based on the CM-SAF SARAH satellite-derived irradiance dataset [71]. The distribution of these generators is proportional to the quality of each site given by the local capacity factor. However, protected sites as listed in Natura2000 [72] are excluded, as well as areas with certain land use types, as specified by [4] from the Corine Land Cover database [73], to avoid, for example, placing wind turbines in urban areas. The maximum water depth for offshore wind turbines is assumed to be $50 \mathrm{~m}$. The maximum installable capacity per country and generator type is then determined by scaling these layouts until one site on the $40 \times 40 \mathrm{~km}^{2}$ lattice reaches the maximum installation density. The theoretical maximum densities would be $10 \mathrm{MW} / \mathrm{km}^{2}$ and $145 \mathrm{MW} / \mathrm{km}^{2}$ for wind and solar respectively, but following [13] we take $20 \%$ and $1 \%$ of these values respectively, in order to take account of competing land uses and minimum-distance regulations in the case of onshore wind turbines. Further validation of the renewable potentials was carried out in [65].

The hydroelectricity generators in this model are fixed to their current size and are split into reservoir and run-of-river generators with river inflow, and pumped hydro storage as pure storage units. Their respective power and energy storage capacities are based on country-aggregated data reported by [74, 75] and the inflow time series are provided by [74]. The power capacities and inflows of hydro reservoir and run-of-river are split in proportion to their respective national shares of installed capacity published by [76].

The model contains two extendable types of stationary electricity storage units: batteries and hydrogen storage. Their charging and discharging efficiencies, as well as cost assumptions for their power and energy storage capacities are taken from [57]. For batteries, it is assumed that the charging and discharging power capacities of the inverter are equal; the energy storage capacity is optimised independently. For hydrogen storage the capacities for the production of hydrogen via electrolysis, the storage in steel tanks and the generation of electricity with fuel cells can all be optimised independently, since hydrogen is also used for non-electric purposes such as methanation and for fuel cell vehicles. Any explicit standing losses are neglected in the model.

In some scenarios synthetic methane can be produced from the hydrogen using the Sabatier process. The methane can then be used in gas turbines, CHPs or in gas boilers for heating. Carbon dioxide for the methane production is sourced using Direct Air Capture (DAC). This conservative assumption was chosen because other carbon sources could not be guaranteed: biogenic sources are needed in sectors not covered in the model, such as aviation, shipping and non-electric industrial demand; capture of $\mathrm{CO}_{2}$ from fossil-burning industry and use in synthetic fuels still results in net emissions; finally, carbon captured from power plants could not be used, since the model does not build enough centralised plants to generate the required carbon dioxide.

DAC reduces the overall efficiency of the methanation because it is an energy-intensive process. Based on figures from [60] (based in turn on private communications with the firm ClimeWorks), $0.23 \mathrm{kWh}_{\mathrm{el}}$ and $1.5 \mathrm{kWh}_{\mathrm{th}}$ are required for each kilogram of $\mathrm{CO}_{2}$ extracted from the atmosphere, which reduces the overall energy efficiency of the methanation from $80 \%$ to $60 \%$ (based on $0.19 \mathrm{kgCO}_{2} / \mathrm{kWh}_{\text {th }}$ for methane).

The differences with the model in [13] are: satellite data is used for the solar PV time series instead of reanalysis data, since this was found to represent low generation in winter more realistically; power and energy capacities for stationary battery and hydrogen storage are optimised independently; PV is split 50-50\% between rooftop and utility installations, with cost changes and a lower discount rate for rooftop PV (see Section 3.8); and electricity can also be generated by CHP units (see 
Section 3.7).

\subsection{Transport demand}

For the transport final energy demand, only transport by road and rail are considered in the model. Aviation, shipping and pipeline transport are not considered. The mechanical drive for transport is assumed to be provided in all cases by electric motors, since electric and fuel cell electric vehicles are the most promising candidates for fossil-free transport.

Transport demand time series are based on hourly vehicle counting statistics from the German Federal Highway Research Institute (BASt) [77], which the BASt has averaged to a weekly profile (see Figure 2) based on the assumption that the profiles change little from season to season. Given the lack of a unified Europe-wide transport profile dataset, this German weekly profile is assumed to be representative of transport demand for all countries in all seasons and replicated for each country, taking account of time zones and summer time. The profiles are scaled to the total road and non-electric rail final energy demand for each country for 2011 taken from the Odyssee database [78], corrected for the assumption that all land-based transport is electrified and for the heating and cooling requirements in electric vehicles.

To account for the fact that electric motors are significantly more efficient in their consumption of electricity than internal combustion engines are in their consumption of fossil fuels, the totals are divided by a country-specific factor (averaging 3.5), giving a total final electric energy transport demand in the model of $1075 \mathrm{TWh}_{\mathrm{el}} / \mathrm{a}$. The country-specific efficiency factors are based on passenger car final energy consumption per $\mathrm{km}$ in 2011 (averaging $0.70 \mathrm{kWh} / \mathrm{km}$ ) from the Odyssee database compared to the plug-to-wheels value of $0.20 \mathrm{kWh} / \mathrm{km}$ for the Tesla Model S, which was on the higher side for the selection of electric cars tested by the US EPA in 2016 [79].

The profiles are then corrected with a temperature-dependent factor for the heating and cooling demand in the vehicles. For both internal combustion engine vehicles (ICEV) and electric vehicles $(\mathrm{EV})$ it is assumed that no climate control is required when the outside temperature is between $15^{\circ} \mathrm{C}$ and $20^{\circ} \mathrm{C}$, and that below or above these temperatures the demand increases linearly with the temperature. For EVs it is assumed that heating increases overall demand by $0.98 \% /{ }^{\circ} \mathrm{C}$, while cooling increases it by $0.63 \% /{ }^{\circ} \mathrm{C}$, based on figures reported for the range of the Tesla Model $\mathrm{S}$ in different conditions on the manufacturer's website [80]. For ICEVs the value for heating is $0.38 \% /{ }^{\circ} \mathrm{C}$ and for cooling is $1.6 \% /{ }^{\circ} \mathrm{C}$, based on approximate figures from the US EPA [79]. The difference in heating demand is a reflection of the fact that the internal combustion engine is a source of waste heat, while for cooling, the driving of the compressor for air conditioning has the same overall efficiency as the engine itself. To correct the hourly profiles, the climate control demand for ICEVs is first subtracted from the total transport demand, yearly profiles are then extrapolated from the weekly profile, then finally the temperature-dependent adjustment for the EV climate control is made to the profiles. These corrections result in a final electric energy transport demand of $1102 \mathrm{TWh}_{\mathrm{el}} / \mathrm{a}$.

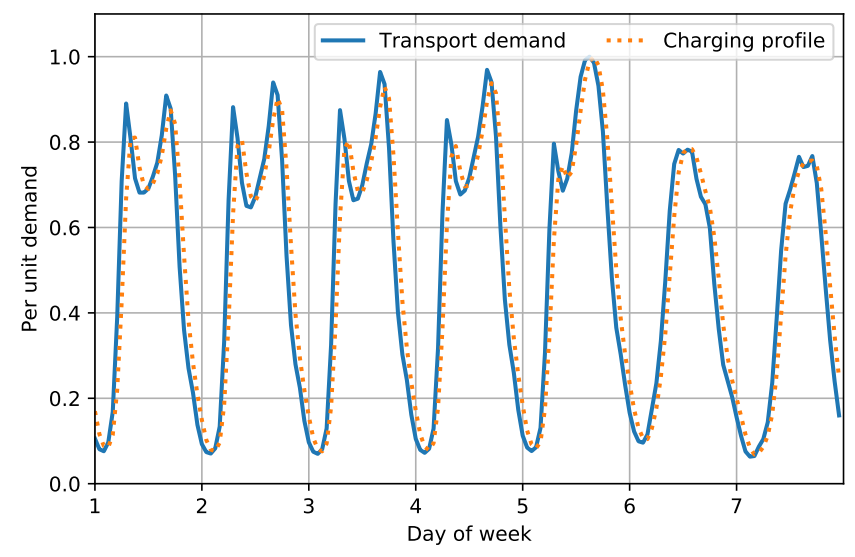

Figure 2: Road transport demand based on statistics gathered by the German Federal Highway Research Institute (BASt) and derived BEV charging profile.

In the basic transport scenario, charging profiles for battery electric vehicles are constructed based on the simple assumption that vehicles plug into the grid after travel and try to charge immediately. This assumes that there is charging infrastructure available at places of work, commerce and in homes. Given that the average daily distance travelled is typically low (averaging around $40 \mathrm{~km}$ per day for passenger cars in Germany [78], corresponding to $8 \mathrm{kWh}$ ) and chargers are assumed to be at least $11 \mathrm{~kW}$ for each vehicle, the charging profiles are spread one third immediately after consumption, one third one hour after consumption and one third two hours after consumption; the resulting charging profile is plotted in Figure 2. The charging profile peaks in the evening at 6-7 pm, raising the Europe-wide electricity-only yearly peak demand from $459 \mathrm{GW}$ to $659 \mathrm{GW}$. Scenarios with demand-side management (DSM) are also considered, as described in the following section.

\subsection{Transport supply}

It is assumed that all road and rail transport demand is either met by electric vehicles (EVs) or by hydrogen-consuming fuel cell electric vehicles (FCEVs), depending on the scenario. The investment in vehicles is not optimised in the model, but given exogenously. The number of passenger vehicles is assumed to be the same as today ( 246 million vehicles, 0.465 per population of 529 million people). The effects of a reduced vehicle fleet are discussed below.

In the scenarios with EVs, all passenger cars are taken to be battery electric vehicles (BEVs); whether road freight is electrified as BEVs, or with electric roads (e.g. overhead pantographs) [81], or on rail, is left open. The BEVs are modelled in aggregate for each country, following the approach in [21, 82]. In the demand-side management (DSM) scenarios, a fixed fraction of cars make a battery capacity of $50 \mathrm{kWh}$ per car available to the model to shift the BEV charging to times which reduce total system costs. $50 \mathrm{kWh}$ corresponds to today's mid-range capacity or today's top-range model (the Tesla S100) with half its $100 \mathrm{kWh}$ capacity reserved as a buffer. The default fraction of cars participating in DSM is $50 \%$; scenarios with $25 \%$ 
and $100 \%$ are also explored. Scenarios where the cars can discharge into the grid (vehicle-to-grid, V2G) are also examined. With $50 \%$ of cars participating, there is $6.15 \mathrm{TWh}$ of storage available to the model, which corresponds to around three quarters of the daily regular electricity consumption; this capacity is ideal for smoothing out the diurnal variations of solar power.

In both DSM and V2G scenarios the BEV state of charge available to the model is forced to be between $75 \%$ and $100 \%$ at 5 am every day (using the variable $\underline{e}_{n, s, t}$ from equation (5)), to meet the expectation of consumers that the battery is reasonably full in the morning before peak usage. The lower limit $75 \%$ was chosen so that the battery has room to be fully charged by PV during the day. This restriction allows demand to be shifted within a day, but prevents the wide-scale synoptic or seasonal shifting of BEV demand.

Each car can charge its battery with an efficiency of $90 \%$ at a maximum rate of $11 \mathrm{~kW}$ (i.e. with a three-phase $400 \mathrm{~V} 16 \mathrm{~A}$ connection); discharging is also assumed to be $90 \%$ efficient. The power availability of the cars, i.e. the percentage connected to the grid at any time, is assumed to be inversely proportional to the demand profile. The profile is affinely transformed so that the average availability is $80 \%$ and the peak availability is $95 \%$. This results in a minimum availability of around $62 \%$. These figures are conservative compared to most of the literature: [82] uses a minimum availability of $80 \%$; [83] calculates that at least $83-92 \%$ of the vehicle fleet in California is parked at any time; fields tests in the United States from 2007 (predating widespread charging infrastructure) [84] showed EVs were parked more than $90 \%$ of the day and plugged in $60 \%$ of the time; [85] reports that in Switzerland the minimum fraction of vehicles which are parked is just under $60 \%$. The very high charging power compared to average consumption (the total charging power is theoretically $2700 \mathrm{GW}$, although the average transport consumption is only $110 \mathrm{GW}$ ) means that reducing this power availability has very little effect on the model; reducing the availability by $50 \%$ has no effect, and a $1 \%$ change to system costs is seen first at a $75 \%$ reduction. $^{2}$ The availability assumptions would only become significant if there were significant changes to consumer behaviour such as a wide-scale (i.e. more than $75 \%$ ) shift to car-sharing, so that the number of vehicles would be much lower and the shared vehicles would be plugged in less often and for shorter periods. However, even the most amibitious scenarios do not consider such a large shift to car sharing; for example, [86] foresees for the United States a reduction in the total number of cars by $23 \%$ by 2035 compared to 2015 , of which half remain in personal ownership and half are automated mobility service vehicles. The autonomous vehicles are still plugged in much of the time outside peak hours [86].

The cost of the car charging infrastructure is calculated following [29], which assumes 1.5 charging points per car, of which $90 \%$ are private costing $200 €$ each and $10 \%$ are public costing $667 €$ each. For 246 million cars in Europe this results

\footnotetext{
${ }^{2}$ This also means that the results will not change if only single phase rather than three-phase connections are available at residential properties.
}

in annual costs of 6.2 billion $€ /$ a. However, as discussed in Section 5.3, this does not include upstream upgrades to electricity distribution networks that may be triggered by the increase in electrical load.

Electric vehicles can be substituted with fuel cell electric vehicles (FCEVs) which convert hydrogen to electricity with an efficiency of $58 \%$. Because there is cheap hydrogen storage in the model, the hydrogen demand for transport represents a large source of flexible demand to the model; this system benefit is offset by the lower efficiency compared to electric vehicles. Based on cost assumptions from [29] of $2.8 €$ per GJ of hydrogen provided, the cost of the hydrogen filling station infrastructure in Europe would be 17.2 billion $€$ /a for a landbased transport system based entirely on FCEVs.

\subsection{Heating demand}

For the heating final energy demand, only low-temperature space and water heating in the residential and service sectors are considered. Heating in the industrial sector is not included in the model and cooking demand is included directly in the electricity demand. Water heating demand is assumed to be constant over the year, whereas profiles for the space heating demand are derived from temperature time series using the degree-day approximation, assuming that the heating demand rises linearly below an average daily temperature of $15^{\circ} \mathrm{C}$. Average daily temperature time series for 2011 for each country are computed from the NCEP CFSR Reanalysis air temperature dataset [69], using the NUTS3 population data as a proxy for the geographical distribution of heat demand within each country; see Figure 3 for a graph of the total European heat demand profile. Intraday profiles, which correspond to typical consumer usage patterns, are based on weekday and weekend profiles derived from heat demand data for Aarhus, Denmark in $[87,88]$.

The water and space heating demand for the residential and service sectors is scaled to energy totals for each country for 2011 taken from the Odyssee database [78]. Some data for the split between water, space and cooking heating is missing for some countries, particularly in the service sector, so here the total for non-electric demand from the sectors was taken from the Eurostat database [89] and split between space/water/cooking according to the average ratios for the countries in the Odyssee database. The average ratios were $79 / 15 / 6 \%$ in the residential sector and 78/14/4\% in the service sector (with $4 \%$ remaining in services for other heating applications). For Switzerland a separate official data source was used [90]. The total final energy heating demand in the model is $3585 \mathrm{TWh}_{\text {th }} / \mathrm{a}$.

In each country the heating demand is split between more rural areas with low heating-per-area-density and more urban areas with high heating-per-area-density. This distinction is made because it is assumed that centralised district heating is only viable in high-density areas, whereas ground-sourced heat pumps are only allowed in low-density areas because of space restrictions [91]. High-density areas are defined as $60 \%$ of all urban demand, since it was determined to be cost-effective to use district heating for this fraction in a selection of European 


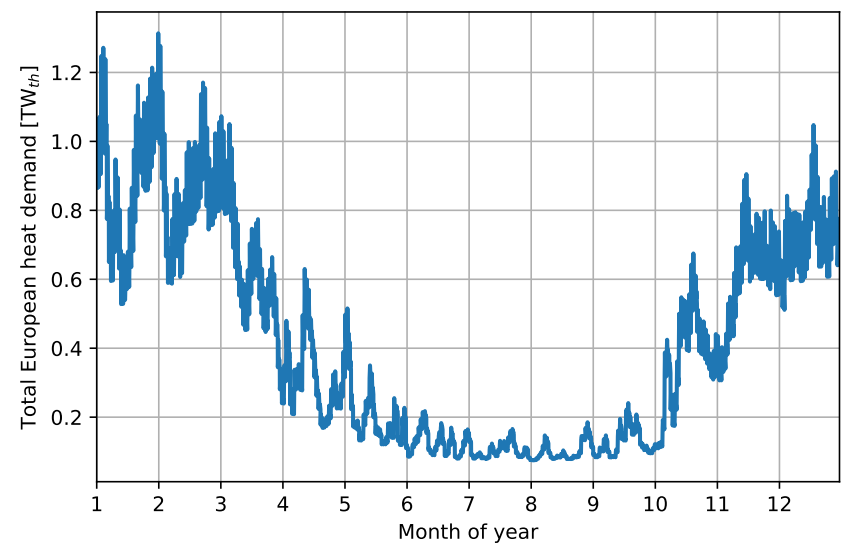

Figure 3: Sum of heat demand profiles from 2011 for all 30 countries based on average daily temperatures in each country using the degree-day approximation.

countries in [92]. In Europe $74.4 \%$ of the population lives in urban areas, so according to this measure, $44.6 \%$ of people live in high-density areas. This fraction agrees with other assessments of the potential penetration of district heating [93].

Heating efficiency measures are considered in the next section.

\subsection{Heating supply}

Depending on the heat density of the area, different technologies are allowed, as summarised in Table 2. In low-density areas only decentralised individual heating units are allowed in the model. For high-density areas, either individual heating units are used or district heating can be turned on to provide heating centrally, depending on the scenario. District heating is allowed in all countries except those at southern latitudes (Portugal, Spain, Italy, Greece and Bulgaria), where heating demand is low enough that district heating is not considered economical.

District heating has the potential advantage that heating units can be built more cheaply at scale and more easily interchanged; in addition, large CHPs and long-term thermal energy storage (LTES) can be used [94]. LTES requires large, wellinsulated hot water tanks in pits containing tens of thousands of cubic metres of hot water, which is only feasible for large heat demand.

District heating is costed with reference to the peak heating demand at $220 € / \mathrm{kW}$, based on the cost for high-density, urban areas from [29]. This roughly agrees with the investment cost of high-density district heating in [92] of $208 € / \mathrm{kW}$ (converted from $2 € / G J$ using the average European peak-to-average ratio for heat demand of 3.57); the figure of $400 € / \mathrm{kW}$ quoted in [27] is more in line with the figure for low-density heat demand of $370 € / \mathrm{kW}$ from [29]. It must also be considered that where district heating replaces individual gas heating, costs are saved by no longer requiring a gas distribution network.

It is assumed that gas distribution networks can be built for all high-density areas and most low-density areas. There is not much literature on the costs for gas distribution as a function of

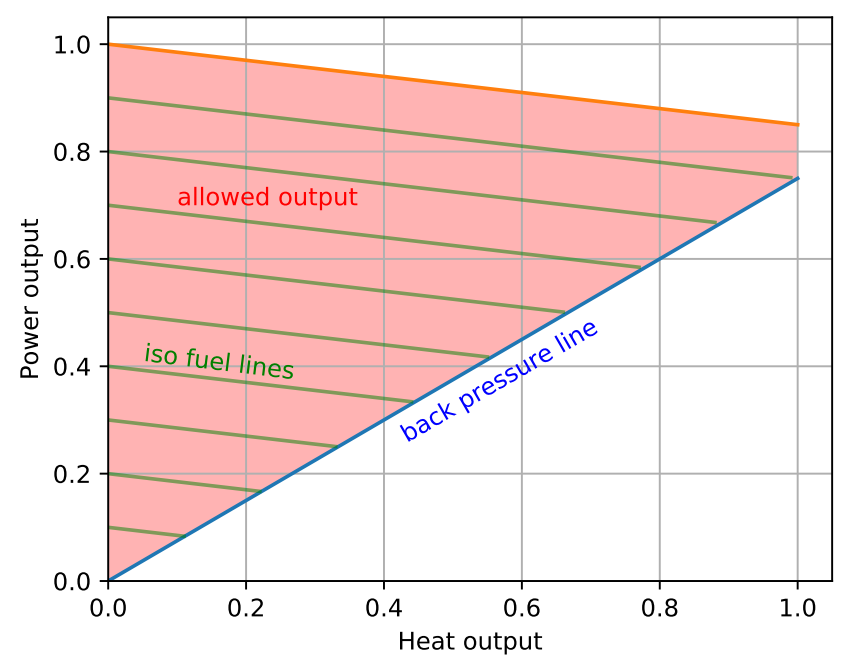

Figure 4: The allowed area of heat and power production for a CHP unit.

heat demand density, so an approximation was made based on the residential network charge of $15 € / \mathrm{MWh}$ in Germany [62]. This converts to an average investment cost of $387 € / \mathrm{kW}$ per peak demand. It is assumed that the peak demand is the main factor when dimensioning the gas infrastructure.

Where gas distribution networks are not feasible because of low demand density or distance from transmission pipelines, liquified gas must be delivered in canisters. Liquified gas is considered preferable to oil for remote areas, given the lower cost of gas and its lower $\mathrm{CO}_{2}$ emissions (which also reduce the cost to consumers given the high $\mathrm{CO}_{2}$ prices seen in the models).

Heat pumps are implemented with a coefficient of performance (COP) that varies with the temperature. It is important to model the varying COP because the COP drops low exactly when the heating demand is high [91]. The relationship between the COP and temperature difference between the heat source and sink $\Delta T=T_{\text {sink }}-T_{\text {source }}$ in degrees Celsius is taken from a 2012 survey [95] (for air-sourced heat pumps: 6.81-0.121 $\Delta T+0.000630 \Delta T^{2}$; for ground-sourced heat pumps: $\left.8.77-0.150 \Delta T+0.000734 \Delta T^{2}\right)$. The sink water temperature was assumed to be $55^{\circ} \mathrm{C}$, following [91], which is sufficient for domestic hot water, but could be reduced for space heating with appropriate large-area radiators. The source air and ground temperatures are taken from the same dataset [69] as for the heating demand. Ground-sourced heat pumps (GSHP) are only allowed in low-density areas because of land restrictions [91]. In high-density areas only air-sourced heat pumps (ASHP) are allowed, since their potentials are not limited. However, noise regulations must be taken into account for siting ASHPs. In cities other heat sources for heat pumps might be available with higher temperatures than the air, such as boreholes or sewage water, but this has not been considered in the limited scope of this study.

The combined heat and power (CHP) model is based on the extraction condensing unit described in [96], which defines a 
Low-density heat demand

\begin{tabular}{llll}
\cline { 3 - 3 } \cline { 3 - 3 } Individual & Individual & Central (District Heating) \\
\hline Gas boiler & & Gas boiler & Gas boiler \\
Resistive heater & Resistive heater & Resistive heater \\
Ground-sourced heat pump & & Air-sourced heat pump & Air-sourced heat pump \\
Solar thermal & Solar thermal & Solar thermal \\
Short-term TES & Short-term TES & Long-term TES \\
& & Combined Heat and Power
\end{tabular}

Table 2: Heating technologies allowed in the different density areas.

feasible operational area for power and heat production shown in Figure 4. The feasible space is bounded at the bottom by the back pressure line with slope 0.75 and bounded at the top by the loss of power per unit of heat production with slope -0.15 , whose slope also defines the iso fuel lines. With no heat production (i.e. in condensing mode), the electrical efficiency of the CHP is $46.8 \%$.

The solar thermal collector model uses the mathematical model from [27], which is based on the geometry of the collectors in relation to the Sun, the downward shortwave radiation flux $G$ (in $\mathrm{W} / \mathrm{m}^{2}$ ) on the collector, ambient temperature $T_{\text {amb }}$ from [69], storage temperature of water $T_{\text {stor }}$, assumed to be $80^{\circ} \mathrm{C}$, the optical efficiency $c_{0}$ and the heat loss coefficient $c_{1}$. The heat generated per $\mathrm{m}^{2}$ is then given by $Q=\eta_{\text {coll }} G$ where the efficiency depends both on the irradiation and the ambient temperature:

$$
\eta_{\mathrm{coll}}=\left[c_{0}-c_{1}\left(\frac{T_{\mathrm{stor}}-T_{\mathrm{amb}}}{G}\right)\right]^{+}
$$

It was assumed that all solar collectors are tilted $45^{\circ}$ to the south which is close to the optimum position to maximize production in winter in European countries. Following [27], we assume $c_{0}=0.8$ and $c_{1}=3 \mathrm{~W} / \mathrm{m}^{2} / \mathrm{K}$. As an example, German collectors yield $532 \mathrm{kWh}_{\mathrm{th}} / \mathrm{m}^{2} / \mathrm{a}$.

The model can also build thermal energy storage (TES), whose parameters are based on insulated hot water tanks. The water tanks are assumed to have a thermal energy density of $46.8 \mathrm{kWh}$ th $/ \mathrm{m}^{3}$, corresponding to a temperature difference of $40 \mathrm{~K}$. The decay of thermal energy is assumed to have a time constant of $\tau=3$ days for short-term TES and $\tau=180$ days for long-term TES, i.e. $1-\exp \left(-\frac{1}{24 \tau}\right)$ of the energy is lost per hour regardless of the ambient temperature. Charging and discharging efficiencies are $90 \%$ due to pipe losses.

Building retrofitting to reduce energy demand for space heating requires a detailed database for each country of the building stock, its current state of insulation and consumer heating behaviour. Since adequate data was not available for each European state, investment in retrofitting was not optimised directly in the model. Instead, a qualitative analysis is given based on available retrofitting costs for Germany [27, 58] and Denmark [97], plotted in Figure 5. These costs, averaged over each $\mathrm{MWh}_{\text {th }}$ of space heating demand, can then be compared to the average marginal cost of space heating in each scenario (the $\lambda_{n, t}$ for the heat bus from equation (2), weighted by the time series

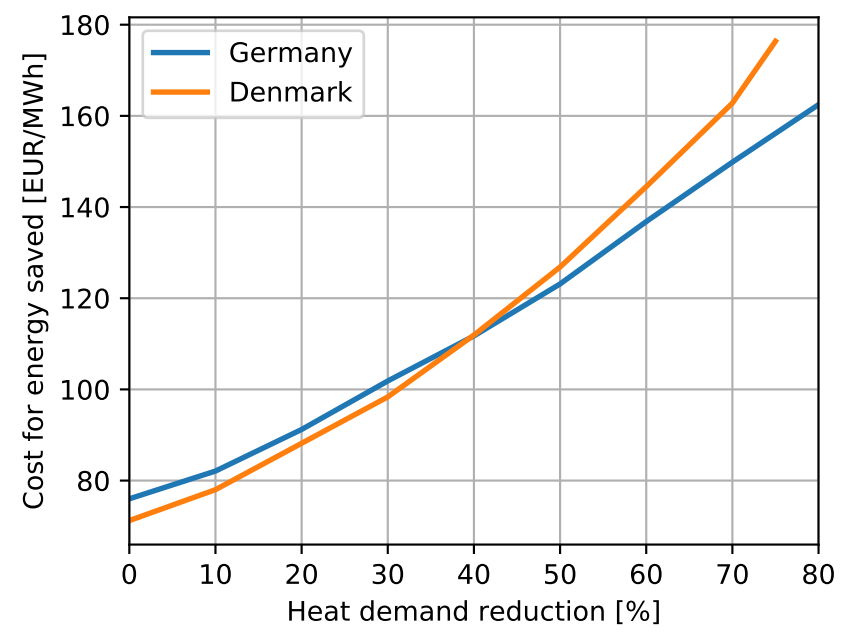

Figure 5: Additional costs, averaged over each $\mathrm{MWh}_{\mathrm{th}}$ of space heating consumption, for building retrofitting to reduce space heating demand by a specific fraction (x-axis). The German data is taken from [27, 58], with a lifetime of 50 years and with the reduction based on 2011 demand; the Danish data is taken from [97] with a lifetime of 30 years and based on 2010 demand; a discount rate of $4 \%$ and FOM of $1 \% /$ a have been used.

for space heating demand), to estimate what level of retrofitting is efficient.

\subsection{Costs}

Investment costs, fixed operation and maintenance (FOM) costs, lifetimes, efficiencies and data sources for all assets are listed in Table 1. Natural gas fuel costs are $21.6 € / \mathrm{MWh}_{\mathrm{th}}$, while gas variable operation and maintenance (VOM) costs are $3 € / \mathrm{MWh}_{\mathrm{el}}$ [54]. Individual heating systems are labelled 'decentral', while heating systems that are connected to district heating networks are labelled 'central'.

Where possible, the costs are oriented towards predictions for 2030, since this is a horizon within which cost projections might be reliable, and also because this is the earliest point at which a $95 \% \mathrm{CO}_{2}$ reduction might be plausible. The costs for generating assets are mostly based on predictions for 2030 from DIW [54], with the exception of solar PV, which has been updated with current industry projections [55] given the fast changing costs; the costs for battery and hydrogen electricity storage come from [57]; the costs of heating sector units are 
taken from $[27,29,58]$. Costs are within the ranges found in other databases [56, 64, 98].

For the annualisation of overnight costs a discount rate of $7 \%$ is used for large, utility and central assets, while a rate of $4 \%$ is used for decentral individual units (including rooftop solar PV and building retrofitting), following the approach in [27, 58]. Solar PV units are split between 50\% for decentral rooftop and $50 \%$ for utility-scale units.

\subsection{Carbon dioxide emissions}

The sectors in the model cover $72 \%$ of the countries' final energy consumption in 2011 (including from international marine bunkers) [89]; the majority of the remaining final energy demand comes from non-electric industrial demand (17\%) followed by shipping (5\%) and aviation (4\%).

The sectors covered in the model emitted 3016 megatonnes of $\mathrm{CO}_{2}\left(\mathrm{MtCO}_{2}\right)$ in 1990 [78], broken down into $1510 \mathrm{MtCO}_{2}$ from electricity generation, $784 \mathrm{MtCO}_{2}$ for land-based transport and $723 \mathrm{MtCO}_{2}$ for heating in the residential and service sectors. These sectors comprised $68 \%$ of the $\mathrm{CO}_{2}$ emissions in 1990 (76\% in 2011), with almost all the rest coming from nonelectric demand in industry, shipping and aviation. A reduction in emissions of $95 \%$ compared to 1990 thus corresponds to a limit of $151 \mathrm{MtCO}_{2} / \mathrm{a}$ for the sectors considered in the model.

The only net $\mathrm{CO}_{2}$ emissions in the model come from the consumption of natural gas in open-cycle gas turbines, combined heat and power plants and gas boilers; $\mathrm{CO}_{2}$ is also captured from the air for methane synthesis. Gas is assumed to have emissions of $0.19 \mathrm{tCO}_{2} / \mathrm{MWh}_{\mathrm{th}}$, so the model can consume at most $795 \mathrm{TWh}_{\mathrm{th}} / \mathrm{a}$ of natural gas.

\section{Results}

In this section different scenarios are presented, which successively add demand and flexibility from the transport and heating sectors to the model to assess the benefits of sector coupling. By adding flexibility in stages, it is possible to understand how each flexibility option impacts and interacts with the system, particularly with respect to wind and solar generation, which dominate the system costs and behaviour.

A $\mathrm{CO}_{2}$ reduction of $95 \%$ compared to 1990 values is enforced for the sum of the sectors considered in each scenario.

To weigh the benefits of sector coupling flexibility against the expansion of cross-border inter-connectors, for each scenario different levels of transmission are examined, including no transmission, where every country is isolated $\left(\mathrm{CAP}_{L V}=0\right.$ in equation (7)), and cost-optimal transmission expansion using overhead lines $\left(\mathrm{CAP}_{L V}=\infty\right)$.

The options activated in each scenario are summarised in Table 3, along with the main indicators for the results: system costs, optimal transmission volume, the $\mathrm{CO}_{2}$ shadow price $\left(\mu_{\mathrm{CO} 2}\right.$ from equation (8)) and the average load-weighted marginal prices $\left(\lambda_{n, t}\right.$ from equation (2)) of electricity and low (L) and high $(\mathrm{H})$ density space heating demand. The breakdowns of the system costs into individual technologies are plotted in Figures 6 and 7.
In the following subsections the results of each scenario are analysed in detail.

\subsection{Electricity only scenario}

In the Electricity scenario none of the transport or heating demand is activated. This allows a comparison with electricityonly scenarios in the literature, in particular with the recent results of some of the authors [13]. If no interconnecting transmission is allowed, then countries must be electrically selfsufficient at all times and balance the fluctuations of wind and solar locally with hydro, gas and significant capacities of stationary battery and hydrogen storage. This drives up the average price of electricity to $85 € / \mathrm{MWh}_{\mathrm{el}}$ and favours generation from solar PV. If cost-optimal interconnecting transmission of $201 \mathrm{TWkm}$ is built, corresponding to transmission volumes around six-and-a-half times today's capacity of 31 TWkm, then cheaper renewables such as onshore wind can be shared between countries, which brings down the average price by $11 \%$ to $76 € / \mathrm{MWh}_{\mathrm{el}}$. It was shown in [13] that the benefits of transmission are highly non-linear: volumes of transmission interconnection only a few times bigger than today's can already lock-in many of the benefits of international integration.

\subsection{Transport scenario}

In the Transport scenario the electrified land transport demand is added to the electricity-only demand without the potential for demand-side management or for vehicles to feed electricity back into the grid. Although the electrical demand increases by $37 \%$, the total costs increase by $41 \%$ in the case of no transmission. This can be traced back to several effects: the transport load profile exacerbates daytime and evening peak loads, increasing the need for peak capacity, and the higher overall load means that renewable sites with good load factors are already filled to potential, so that worse sites must be exploited. The effect of the profile (high daytime demand, very low night demand, see Figure 2) is also visible in the stronger preference for solar PV compared to wind (see Figure 6), although PV cannot meet the evening peak without storage.

\subsection{Transport with Demand-Side Management from BEVS}

In the Demand-Side Management (DSM) scenarios, fractions of the Battery Electric Vehicles (BEVs) are allowed to shift their charging to the times when electricity is cheapest (which corresponds to the charging times which minimise the total system costs), but do not discharge back into the electricity grid. Each vehicle is assumed to make a $50 \mathrm{kWh}$ battery available to their system, so that, for example, the DSM-25 scenario corresponds to $25 \%$ of the vehicles participating in DSM, or all vehicles participating, but only making $12.5 \mathrm{kWh}$ available for DSM.

From Figure 6 it is clear that allowing DSM significantly reduces the overall system costs compared to the Transport scenario, with a total reduction of 14\% in the DSM-100 scenario. Much of the benefit is already accrued in the DSM-25 scenario, which has $10 \%$ lower costs than the Transport scenario. Thus 


\begin{tabular}{|c|c|c|c|c|c|c|c|c|c|c|c|c|c|c|c|c|c|c|c|}
\hline Scenario & 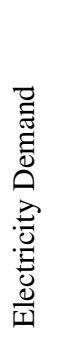 & 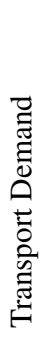 & 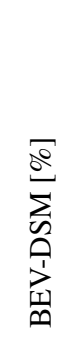 & 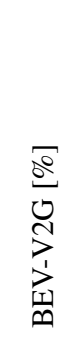 & 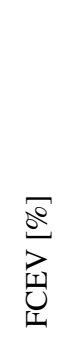 & 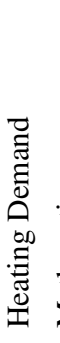 & 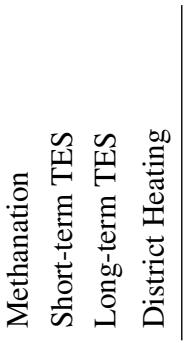 & 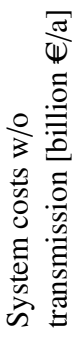 & 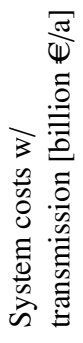 & 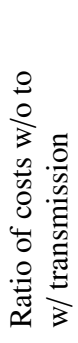 & 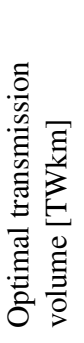 & 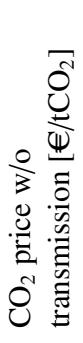 & 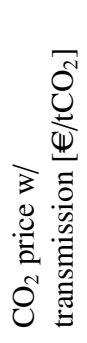 & 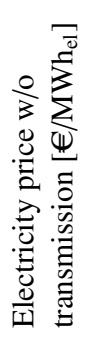 & 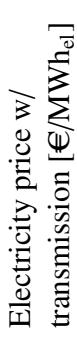 & 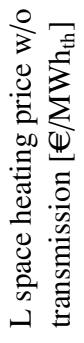 & 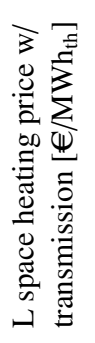 & 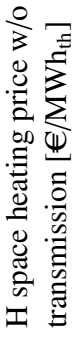 & 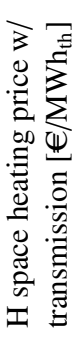 \\
\hline Electricity & $\checkmark$ & & & & & & & 228 & 179 & 1.27 & 201 & 357 & 136 & 85 & 76 & & & & \\
\hline Transport & $\checkmark$ & $\checkmark$ & & & & & & 322 & 262 & 1.23 & 267 & 371 & 145 & 84 & 74 & & & & \\
\hline DSM-25 & $\checkmark$ & $\checkmark$ & 25 & & & & & 289 & 233 & 1.24 & 253 & 345 & 133 & 84 & 75 & & & & \\
\hline DSM-50 & $\checkmark$ & $\checkmark$ & 50 & & & & & 283 & 229 & 1.24 & 248 & 335 & 130 & 84 & 75 & & & & \\
\hline DSM & $\checkmark$ & $\checkmark$ & 100 & & & & & 277 & 224 & 1.24 & 243 & 324 & 127 & 44 & 76 & & & & \\
\hline V2G-25 & $\checkmark$ & $\checkmark$ & 25 & 25 & & & & 279 & 228 & 1.23 & 232 & 348 & 122 & 83 & 72 & & & & \\
\hline V2G-50 & $\checkmark$ & $\checkmark$ & 50 & 50 & & & & 267 & 219 & 1.22 & 210 & 345 & 114 & 82 & 71 & & & & \\
\hline V2G-100 & $\checkmark$ & $\checkmark$ & 100 & 100 & & & & 251 & 207 & 1.21 & 177 & 342 & 114 & 83 & 71 & & & & \\
\hline FC-25 & $\checkmark$ & $\checkmark$ & & & 25 & & & 330 & 269 & 1.23 & 267 & 378 & 141 & 81 & 72 & & & & \\
\hline FC-50 & $\checkmark$ & $\checkmark$ & & & 50 & & & 343 & 282 & 1.22 & 267 & 377 & 132 & 79 & 69 & & & & \\
\hline FC-100 & $\checkmark$ & $\checkmark$ & & & 100 & & & 375 & 313 & 1.20 & 273 & 379 & 122 & 77 & 67 & & & & \\
\hline Heating & $\checkmark$ & $\checkmark$ & & & & $\checkmark$ & & 699 & 527 & 1.33 & 549 & 1184 & 682 & 118 & 85 & 153 & 112 & 61 & 14 \\
\hline Methanatio & $\checkmark$ & $\checkmark$ & & & & $\checkmark$ & $\checkmark$ & 620 & 514 & 1.21 & 457 & 509 & 434 & 77 & 75 & 106 & 94 & 08 & 94 \\
\hline TES & $\checkmark$ & $\checkmark$ & & & & $\checkmark$ & $\checkmark \checkmark$ & 612 & 510 & 1.20 & 458 & 504 & 422 & 77 & 75 & 104 & 92 & 105 & 9 \\
\hline Central & $\checkmark$ & $\checkmark$ & & & & $\checkmark$ & $\checkmark$ & 585 & 499 & 1.17 & 443 & 527 & 460 & 77 & 75 & 104 & 94 & 92 & 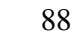 \\
\hline Central-TES & $\checkmark$ & $\checkmark$ & & & & $\checkmark$ & $\begin{array}{llll}\checkmark & \checkmark & \checkmark & \checkmark\end{array}$ & 562 & 479 & 1.17 & 411 & 497 & 413 & 75 & 73 & 101 & 90 & 79 & 76 \\
\hline All-Flex & $\checkmark$ & $\checkmark$ & 50 & 50 & & $\checkmark$ & $\checkmark \checkmark$ & 550 & 468 & 1.18 & 398 & 473 & 416 & 73 & 70 & 101 & 92 & 102 & 92 \\
\hline All-Flex-Central & $\checkmark$ & $\checkmark$ & 50 & 50 & & $\checkmark$ & $\checkmark \begin{array}{llll}\checkmark & \checkmark & \checkmark & \checkmark\end{array}$ & 504 & 440 & 1.15 & 359 & 463 & 407 & 72 & 69 & 98 & 91 & 78 & $7 \xi$ \\
\hline
\end{tabular}

Table 3: Definition of scenarios in terms of activated options (left); major indicators for results (right). BEV-DSM corresponds to the fraction of passenger cars which are allowed to shift their charging to cheaper times; BEV-V2G is the fraction of passenger cars which are allowed to feed back into the grid if it is profitable. FCEV gives the fraction of transport demand which is met by fuel cell electric vehicles. Results are reported without transmission and with optimal transmission.

only $25 \%$ of vehicles have to participate in DSM to see the majority of the system benefit.

The cost reduction is seen primarily in the reduced investment in stationary storage (both battery and hydrogen storage), which also leads to lower efficiency losses and therefore lower investment in renewable generators. With optimal transmission capacity, the need for stationary batteries is entirely eliminated. The use of DSM also favours a slightly higher solar share, because the BEV charging can easily be shifted to peak PV times.

\subsection{Transport with Vehicle-To-Grid from BEVs}

In the Vehicle-To-Grid (V2G) scenarios different fractions of the BEVs are allowed to not only shift their charging time, but also to discharge electricity back into the grid at times which are profitable. This essentially makes battery capacity available to the system without any additional investment (since the costs of the vehicles are excluded from our consideration), but it is not free, since the vehicle owners receive a payment from the system corresponding to the price difference between the market price at charging and discharging times.

With all vehicles participating in the V2G-100 scenario, the total system costs are reduced a total of $22 \%$ compared to the Transport scenario with no transmission, to a level that is just
$10 \%$ above the cost of the Electricity scenario. With each increase in V2G share, $25 \%$ to $50 \%$ to $100 \%$, there is a substantial cost saving, although the saving is bigger with no transmission than the case with optimal transmission. V2G leads to the complete elimination of stationary battery storage and the successive elimination of hydrogen storage. With all vehicles participating in $\mathrm{V} 2 \mathrm{G}$ and optimal transmission capacity there is no stationary storage at all; in this case there is increased investment in solar PV and an almost complete elimination of expensive offshore wind. The benefits of V2G are simply due to the sheer volume of storage made available to the system: 12.3 TWh, which is 1.5 days' worth of electricity demand. This allows ample capacity to smooth out diurnal fluctuations, which is reflected in the higher shares of solar PV in the energy mix.

The system benefits of $\mathrm{V} 2 \mathrm{G}$ are also reflected in other indicators. With optimal transmission the shadow price of $\mathrm{CO}_{2}$ drops to $114 € / \mathrm{tCO}_{2}$ in the V2G-100 scenario, which is $16 \%$ less than the value in the Electricity scenario. V2G also reduces the need for interconnecting transmission, with the optimal capacity dropping to $12 \%$ below the Electricity scenario.

Such high levels of DSM and V2G may however be undesirable for other reasons, such as inconvenience for consumers and the increased wear-and-tear on battery components. Although vehicle owners are compensated both for DSM and V2G ac- 


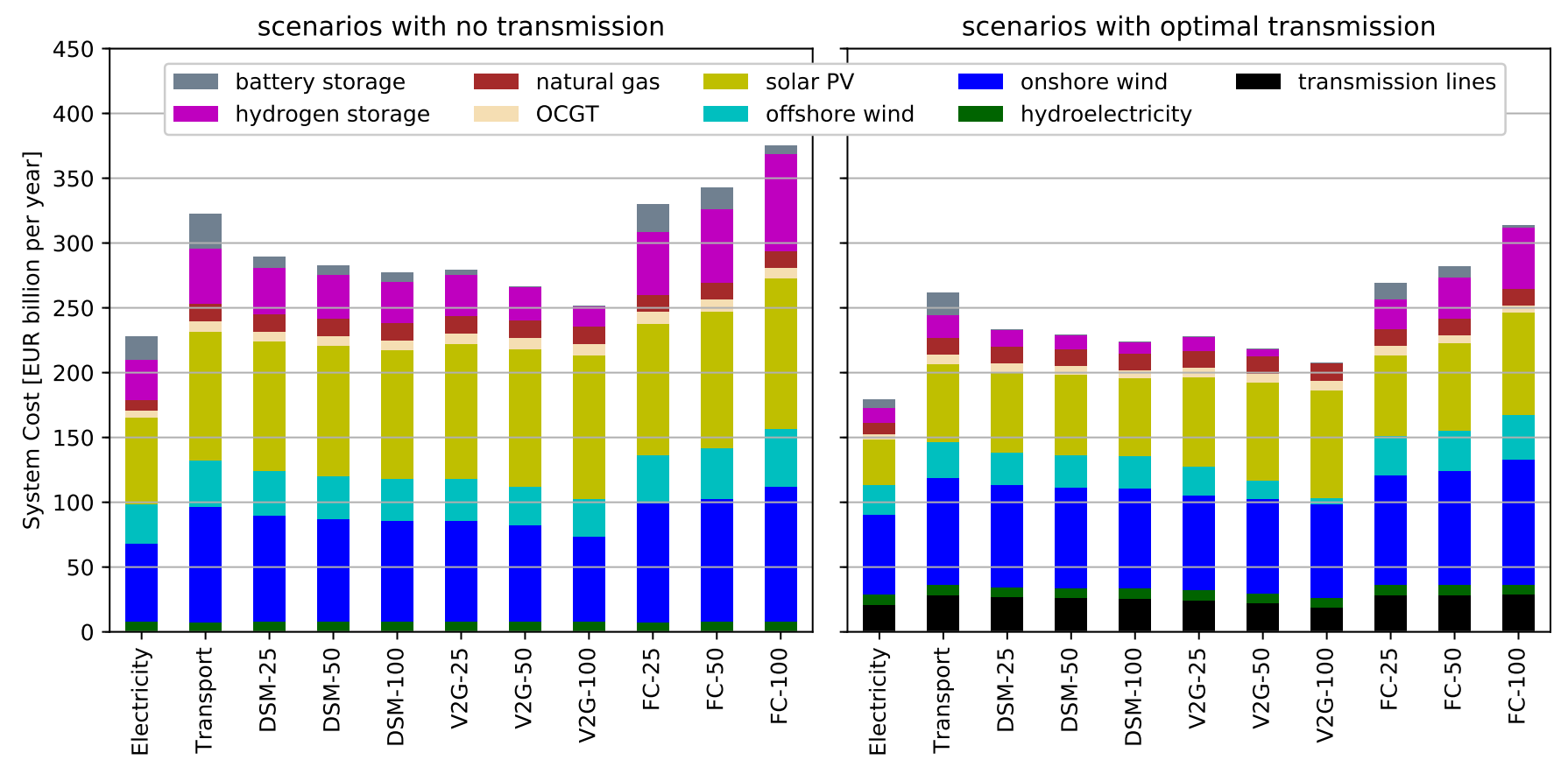

Figure 6: Total annual system costs for the different scenarios with electricity and transport demand, with no interconnecting transmission (left) and optimal interconnecting transmission (right). Note that costs do not include distribution network costs. 'Hydrogen storage' includes the costs of storage tanks, electrolysis and fuel cells.

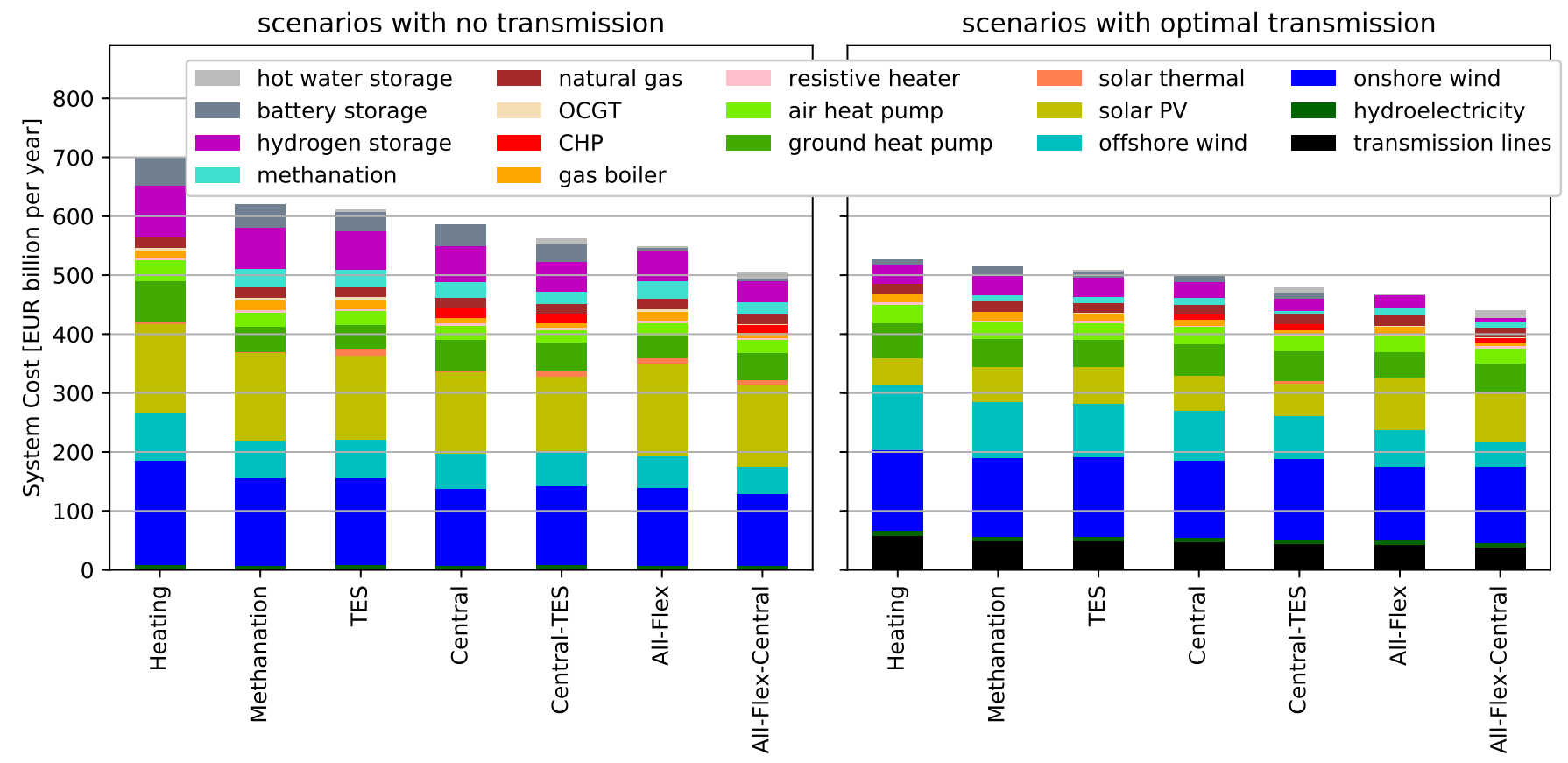

Figure 7: Total annual system costs for the different scenarios with electricity, transport and heating demand, with no interconnecting transmission (left) and optimal interconnecting transmission (right). Note that costs do not include distribution network costs.

cording to market prices, this may not be sufficient to cover their costs. However, as these results demonstrate, there are already significant system benefits if only a fraction of vehicles participate in DSM and V2G.

Furthermore, the way the BEV batteries are used in the
V2G scenarios does not involve the regular deep-discharge cycling that tends to degrade battery performance (at least in the country-aggregated profiles; individual consumption patterns may lead to deeper discharging, but the consumers themselves are responsible for this). Figure 8 shows the aggregated bat- 


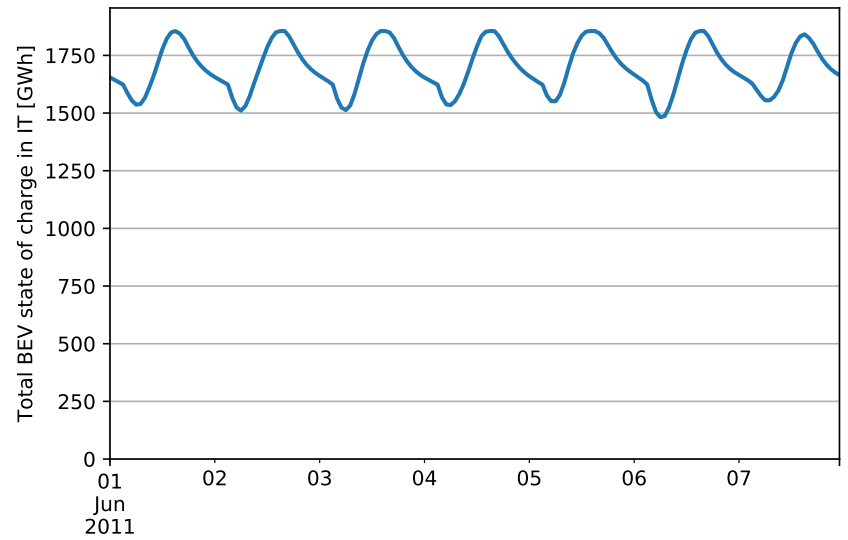

Figure 8: The battery electric vehicle total state of charge in Italy for the scenario V2G-50 during a sunny two-week period. The total energy capacity of all BEVs is $1855 \mathrm{GWh}$.

tery state of charge over a two-week sunny period in Italy from the scenario V2G-50. While charging during the midday PV peak and discharging for the evening electricity and transport demand peak is visible, the changes in energy are small compared to the total vehicle energy capacity; in addition, the requirement that the state of charge is above $75 \%$ at 5 am every day keeps the overall level high and prevents the use of BEVs for smoothing variable renewables over periods longer than a day. If more than half of today's passenger car fleet were made redundant by shared autonomous vehicles, this picture would change because the available battery capacity would be lower, but such dramatic changes in consumer behaviour are considered unlikely [86].

\subsection{Transport with Fuel Cell Electric Vehicles}

In the Fuel Cell Electric Vehicle (FCEV) scenarios fractions of the electric vehicles are replaced with vehicles that use onboard fuel cells consuming hydrogen. Since hydrogen is cheaper to store than electricity, the demand for hydrogen represents a large time-shiftable demand to the system that can be used to balance synoptic and seasonal variations in solar and wind feed-in. On the other hand, the efficiency of the electrolysis $(80 \%)$ and the fuel cell conversion of hydrogen back to electricity $(58 \%)$ is much lower than for battery charging and discharging ( $90 \%$ and $90 \%$ respectively).

In each of the FCEV scenarios, with the fraction of FCEVs ranging from $25 \%$ to $100 \%$, the total system costs are higher than the all-electric Transport scenario, rising to $16 \%$ higher in the FCEV-100 scenario. The higher costs are driven by higher investment in electrolysis devices and hydrogen storage, and more investment in wind and solar to supply the higher energy demand. These cost increases are not offset by the lower investment in stationary battery storage. These results show that the higher energy demand resulting from the lower round-trip efficiency of FCEVs increases costs more than they are reduced by the large shiftable electrolysis demand. On the positive side, the shiftable demand decreases the average electricity price be- low the level in any of the other transport or electricity-only scenarios.

To the additional costs of FCEVs must also be added the higher costs of the vehicles themselves [29] and the costs of the hydrogen distribution system, which was calculated in Section 3.5 to be around 11 billion $€$ /a more for a $100 \%$ FCEV scenario than the charging infrastructure for a $100 \% \mathrm{BEVs}$ scenario.

These results indicate that the FCEVs are not beneficial from a system point of view and should be restricted to applications where the high energy density of hydrogen is required, such as for long-range journeys or for heavy duty vehicles (e.g. haulage trucks) on routes where electrification of roads (e.g. with overhead pantographs) is not possible.

\subsection{Heating scenario}

In the Heating scenario, the heating demand is added to both the electricity and transport demand without adding any extra flexibility options, such as BEV DSM, V2G, thermal energy storage (TES), power-to-gas (P2G) feeding into the natural gas network or district heating in densely populated urban areas.

The addition of heating not only increases the energy demand in the model (adding $3585 \mathrm{TWh}_{\mathrm{th}} / \mathrm{a}$ to the transport and electricity demand of $4062 \mathrm{TWh}_{\mathrm{el}} / \mathrm{a}$ ), but it also requires new infrastructure to meet the heating demand. Given the $95 \% \mathrm{CO}_{2}$ reduction target, much of the heating demand has to be met by converting renewable electricity to heating, primarily using heat pumps but also using resistive heaters (i.e. electric boilers).

With no transmission, the total system costs increase by $117 \%$ compared to the Transport scenario. Heat pumps (air-sourced in densely-population areas, ground-sourced elsewhere) make up $15 \%$ of the total costs.

In Figure 9 the heat supply for each scenario with no transmission is plotted in terms of yearly energy contribution (top) and in terms of the peak power capacity (bottom). The supply is split between the low-density and high-density demand areas. In the Heating scenario, the heating energy provision is dominated by heat pumps, thanks to their efficient use of electricity, but gas boilers provide the most heating power capacity (enough to cover $58 \%$ of the peak heating demand).

This discrepancy can be explained by examining, for example, the available electricity generation and heat supply in Germany during a cold week of the year; see the lefthand plots of Figure 10. At the start of this week it is cold, so that the heating demand is high, while the COP of heat pumps is low; at the same time there is very little low-marginal cost wind and solar available. As a result, the heat pumps are only used when there is a peak of solar PV, and at other times gas boilers must step in to provide backup energy. At these times resistive heaters would also be too expensive because of the high price of electricity and their low efficiency compared to heat pumps.

This means that for buildings supplied by individual heating units, a cost-effective system is for heat pumps to provide the bulk of the yearly heating demand and for gas boilers to provide backup capacity for cold spells. This is more cost-effective than providing all heating demand with heat pumps or resistive heaters, since this would require a large backup OCGT fleet 

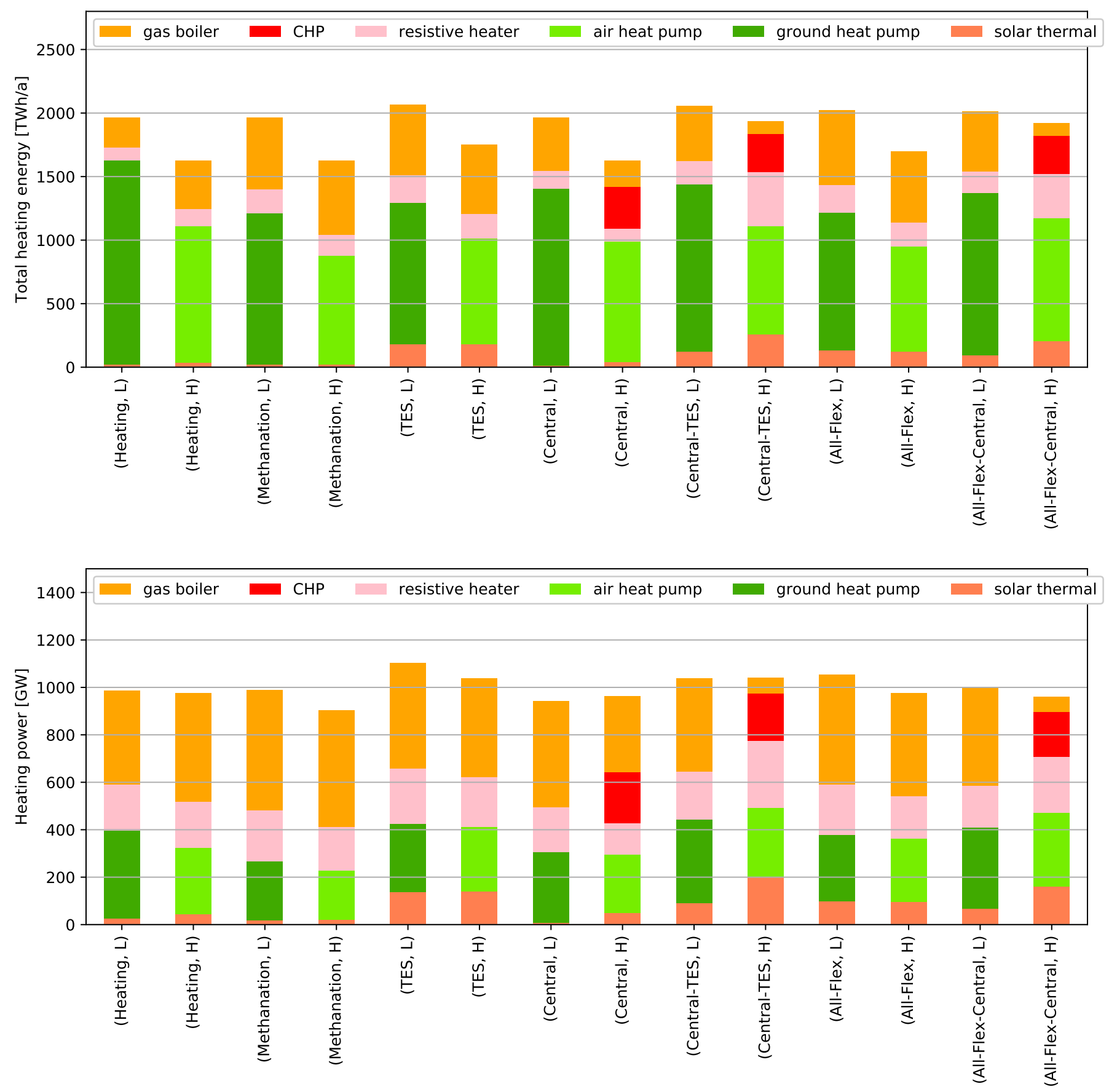

Figure 9: Heating total energy arriving at the heat buses (top) versus heating power capacity (bottom) for each heating scenario, split by the heating provision in low-density areas (L) versus high-density areas (H). No electricity transmission is assumed for these results.

to meet the peak electricity demand, which is less efficient. It does, however, require multiple heating technologies for each building.

This reveals a significant difference between the economics driving the electricity sector versus the heating sector: the heating demand in Europe is much more strongly and seasonally peaked than the electricity demand (refer back to Figure 3 for the yearly heating profile) making the balance between socalled 'base load' and 'peaking' heat provision more skewed in favour of peaking plant.

The heating demand is also more strongly seasonal than the wind in Europe (which also peaks in winter) and is anticorrelated with the seasonality of solar energy in Europe. This mismatch helps to further explain why the total system costs of the Heating scenario are disproportionately higher (given the change in energy demand) than the Transport scenario.

With no transmission, the high average marginal price of supplying space heating demand $\left(153 € / \mathrm{MWh}_{\text {th }}\right.$ in low-density and 

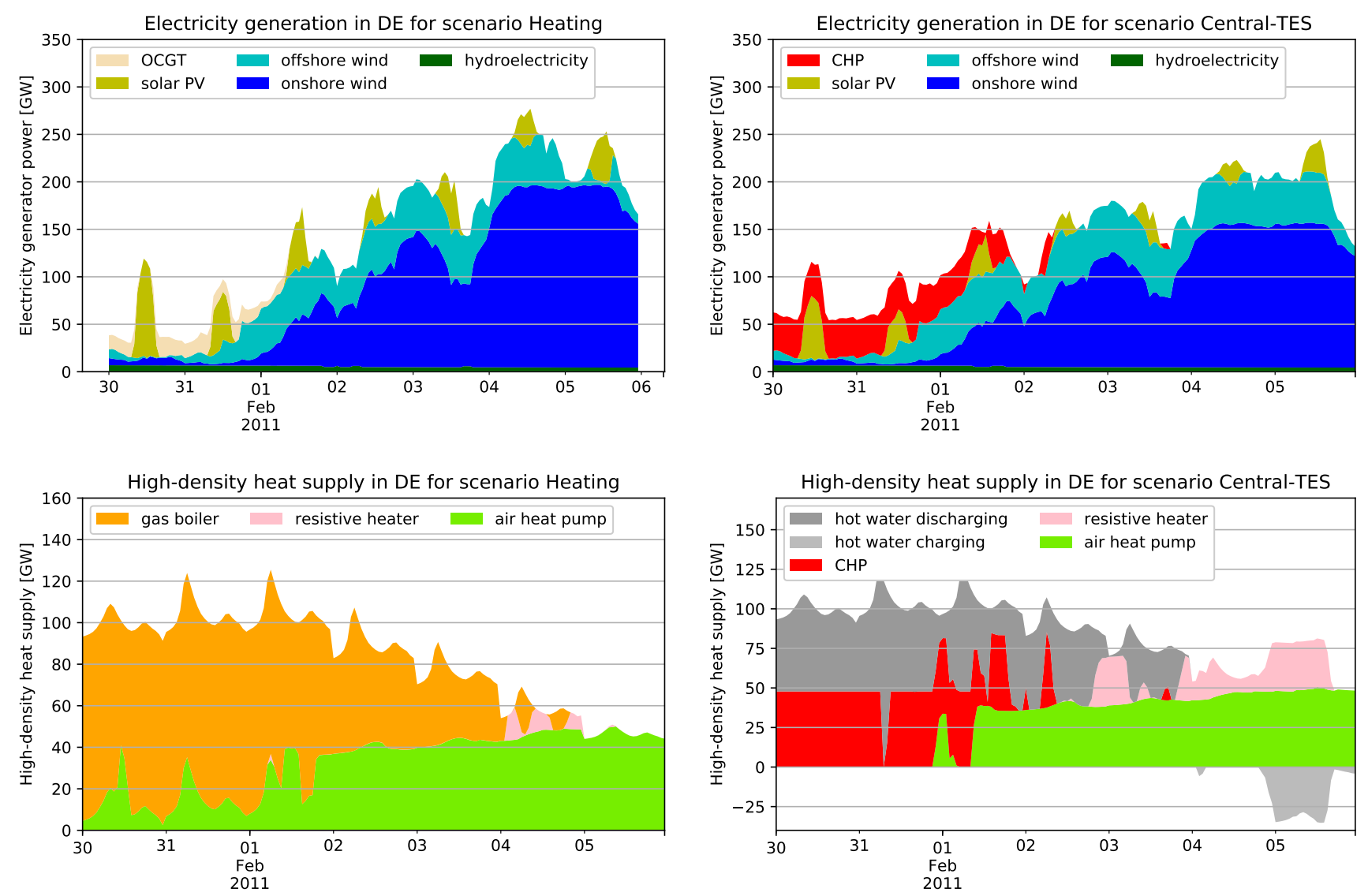

Figure 10: Electricity supply ignoring storage (top) and heating supply in densely-population areas (bottom) for the Heating scenario (left) and the Central-TES scenario (right) in Germany during a week that includes the coldest days of the year. No transmission is assumed for these results.

$161 € / \mathrm{MWh}_{\text {th }}$ in high-density areas) is sufficiently high, particularly when approximate gas distribution network costs of $15 € / \mathrm{MWh}_{\text {th }}$ and/or taxes are added, to justify retrofitting buildings to reduce heat demand by between $70 \%$ and $80 \%$, based on Figure 5 and assuming similar characteristics to Germany and Denmark. This also assumes that the marginal price remains constant as space heating demand is reduced; this assumption might be warranted, given that the high price is caused by the shape of the heating profile and the technology mix, but on the other hand the price might go down because the $\mathrm{CO}_{2}$ limit is easier to meet with lower energy demand, thus only justifying a slightly lower rate of demand reduction. With optimal transmission, the marginal price for space heating is $28 \%$ lower, resulting in a lower rate of retrofitting.

The $\mathrm{CO}_{2}$ shadow price, reflecting the marginal cost of further reducing emissions, is high at $1184 € / \mathrm{tCO}_{2}$ in this scenario with no transmission. This high price is a direct reflection of the high price paid for energy in the model (see Table 3), versus the low fuel cost of natural gas $\left(21.6 € / \mathrm{MWh}_{\mathrm{th}}\right)$, which thus requires a high $\mathrm{CO}_{2}$ price to justify avoiding natural gas. As energy becomes cheaper in the following scenarios, so the $\mathrm{CO}_{2}$ price goes down.

As interconnecting transmission is expanded to its optimal level, costs reduce by $25 \%$ and there is a substantial shift of energy generation from solar PV to wind, since the synoptic variability of wind can now be balanced in space by the grid. The investments in stationary battery and hydrogen storage are also significantly reduced. In the left graphic of Figure 11 the breakdown of the system costs is plotted as the restriction on transmission $\left(\mathrm{CAP}_{L V}\right.$ from equation (7)) is relaxed to its optimal level. As in the Electricity scenario (see also [13]), the cost reduction is non-linear as transmission is expanded. Thus, despite the fact that the optimal level of transmission is very high (173\% higher than the Electricity scenario), $66 \%$ of cost savings are already achieved with a compromise expansion of inter-connecting capacity to $125 \mathrm{TWkm}$, which is four times today's net transfer capacities (NTC). The European regulator ACER believes that today's NTC could be doubled if congestion were managed more effectively [99]; a further doubling of cross-border capacities through grid expansion is already foreseen by the official planning process by 2030 [100], but not in exactly the same places as seen in this model.

\subsection{Methanation scenario}

In the Methanation scenario the conversion of hydrogen to methane is allowed, which can then be fed into the natural gas network for use both in the heating and electricity sectors. Since the carbon dioxide required for the methanation is captured from the air, the methanation has a low overall efficiency 


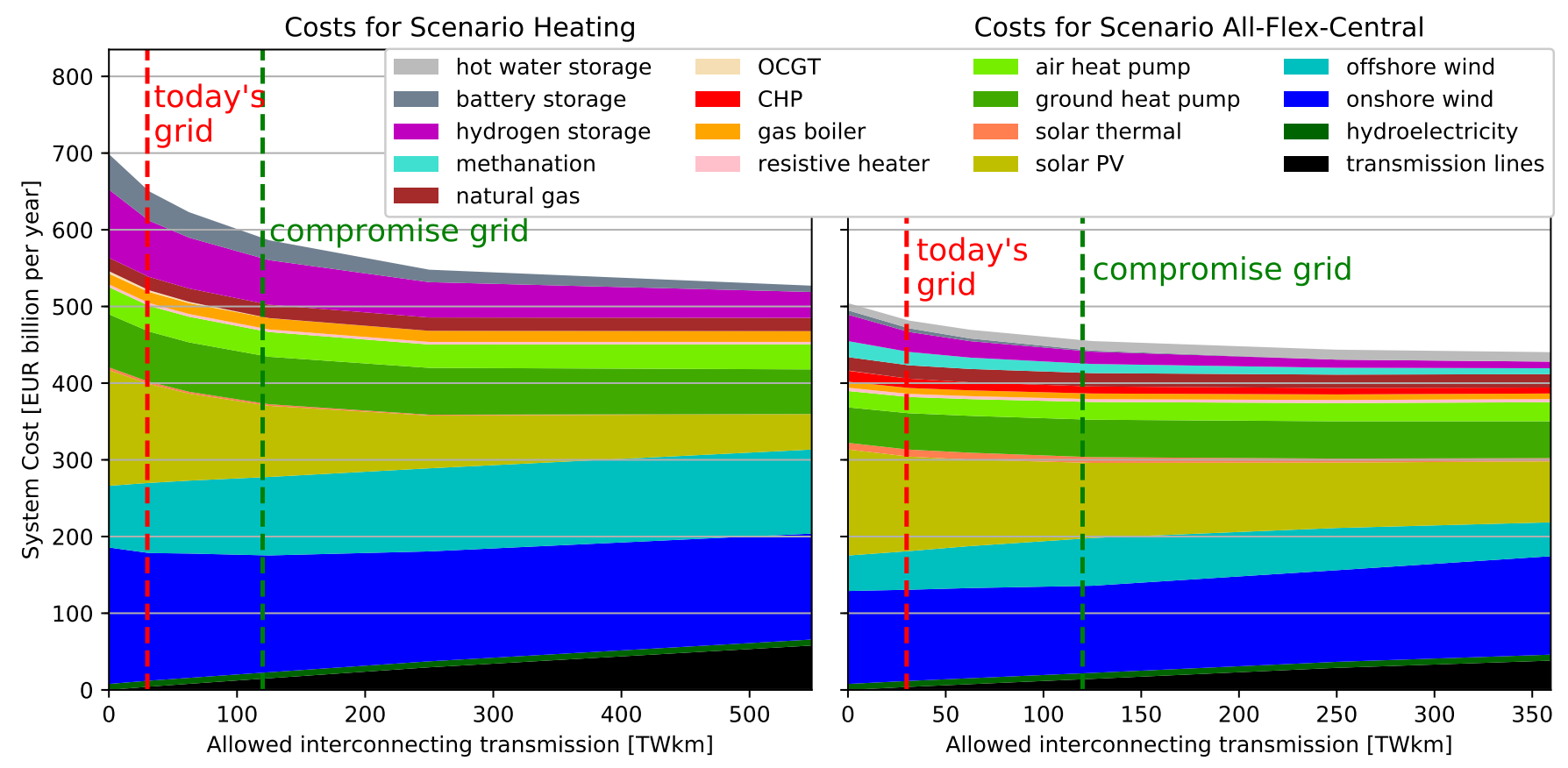

Figure 11: Total yearly system costs as a function of the allowed inter-connecting transmission capacity $\left(\mathrm{CAP}_{L V}\right.$ from equation $\left.(7)\right)$, assuming that transmission is costed as overhead lines. The left graphic shows the Heating scenario and the right graphic the All-Flex-Central scenario. The right axis of each graphic marks the optimal level of grid expansion, which is different in each scenario.

$(60 \%)$, but the resulting methane is extremely valuable to meet the peak heating demand.

Despite the costs of the methanation equipment, total system costs reduce by $11 \%$ compared to the Heating scenario. In the heating sector, a substitution of heat pumps with gas heating can be observed in Figure 9. Significantly reduced $\mathrm{CO}_{2}$ prices and average marginal prices for electricity and heating are also seen in Table 3. Furthermore, the benefit of transmission reinforcement is weakened, since the methanation allows the use of cheap gas storage to smooth synoptic and seasonal variations of renewables. Optimal transmission reduces the total systems costs by only $17 \%$, compared to $25 \%$ in the Heating scenario, and the optimal transmission volume is also lower.

The total volume of synthetic methane produced with no transmission is $708 \mathrm{TWh}_{\text {th }}$, compared to $795 \mathrm{TWh}_{\text {th }}$ from natural gas. With optimal transmission the volume of synthetic methane reduces to $263 \mathrm{TWh}_{\text {th }}$ as transmission smoothes more synoptic variations of wind.

\subsection{Thermal energy storage scenario}

In the Thermal Energy Storage (TES) scenario small hot water tanks are added to the Methanation scenario with a short time constant of $\tau=3$ days.

As can be seen from Figure 9, TES enables a higher share of heating from solar thermal collectors, since the heat can be shifted to hours of higher heat consumption. (Since most solar thermal collectors are installed with TES already, the exclusion of TES from the previous scenarios was somewhat contrived.) However, the thermal losses of the TES mean that more heat must be provided. As a result, the system costs are lowered by just $1.3 \%$ compared to the Methanation scenario.

In total 57 million cubic metres of TES is built in this scenario, averaging 0.108 cubic metres per citizen.

\subsection{Central scenarios}

In the Central scenario, heating demand in denselypopulated areas is served with district heating rather than individual heating units. This enables large combined heat and power plants (CHPs) to be deployed (see Table 2) and the larger scale of all heating units reduces costs (see Table 1). This leads to a reduction in total costs of $6 \%$ compared to the Methanation scenario, on which this scenario is based. Figure 9 shows that CHPs do indeed take over some of the heating supply provided previously by gas boilers.

Another major advantage of district heating is seen when Long-term TES (LTES) is allowed in the Central-TES scenario. The large, well-insulated water tanks used for LTES in the district heating network have a heat decay time constant of $\tau=180$ days, which allows heat to be shifted seasonally. This results in a higher share of solar thermal (see Figure 9), which is used to charge the LTES in summer/autumn, and more usage of resistive heaters when electricity prices are low. In the areas with district heating, the total volume of hot water tanks in LTES is 3.1 billion cubic metres, averaging to 13 cubic metres per citizen.

The LTES can then be used to supply heat during cold periods, as is shown in the example for Germany's cold spell on the righthand side of Figure 10. The majority of heat during the 
coldest times comes from LTES, with the remainder covered by CHPs; gas boilers have been almost totally eliminated.

The benefit of LTES can also be seen in the drop in the average space heating price in high density areas from $92 € / \mathrm{MWh}_{\text {th }}$ in the Central scenario, to $79 € / \mathrm{MWh}_{\text {th }}$ in the Central-TES scenario.

The annualised cost of building and maintaining the district heating network to meet its total peak load of $548 \mathrm{GW}_{\text {th }}$ is 10 billion $€ /$ a according to our cost assumptions. However, a gas distribution network is no longer needed in areas with highdensity heating demand, and this reduces annual costs by 20 billion $€ / a$, more than offsetting the cost of the district heating network and further contributing to the attractiveness of district heating. The cost benefits of district heating are also maintained with optimal transmission.

\subsection{Scenarios with all flexibility options}

In the final scenarios All-Flex and All-Flex-Central, all flexibility options are activated, including 50\% BEV-DSM, 50\% BEV-V2G, methanation and TES.

The total costs in the scenario All-Flex-Central with no transmission are $28 \%$ lower than the Heating scenario, and $17 \%$ cheaper than the Heating scenario with optimal transmission. Much of the cost reduction in the All-Flex-Central scenario comes from a reduced need for stationary battery storage, hydrogen storage and methanation, thanks to the availability of LTES and BEV-V2G. The production of synthetic methane drops to $475 \mathrm{TWh} / \mathrm{a}$ with no transmission and $184 \mathrm{TWh} / \mathrm{a}$ with optimal transmission, which is around one third lower than the values in the Methanation scenarios. The daily smoothing provided by BEV-V2G also makes a larger share of solar PV cost efficient in the All-Flex scenarios.

The only difference between the Central-TES and All-FlexCentral scenarios is the introduction of $50 \%$ BEV-DSM and BEV-V2G. With no transmission, this reduces costs by 58 billion $€ / \mathrm{a}$. This is almost identical to the cost reduction of 55 billion $€ /$ a between the Transport and V2G-50 scenarios; similar changes in technology are also seen (more solar, less electricity storage). This is an indication that the benefits of transport flexibility (largely on daily time scales) are independent from the benefits of heating flexibility (largely on synoptic and seasonal time scales). This effect was also seen in [93].

Transmission is still beneficial in these scenarios, but the benefit is much weaker: the ratio of the costs with and without optimal transmission drops from 1.33 in Heating to 1.15 in All-Flex-Central. All-Flex-Central with no transmission is cheaper than Heating with optimal transmission, but All-FlexCentral with optimal transmission is the cheapest scenario of all.

The optimal transmission volume of $359 \mathrm{TWkm}$ is also much reduced. As can be seen from the righthand graphic in Figure 11 , both the drop in system costs and the change in system composition as transmission is expanded are less dramatic than in the Heating scenario in the lefthand graphic. The compromise grid (four times today's NTC) already captures $78 \%$ of the cost benefit of optimal transmission. The technology choices also remain mostly stable as the transmission volume is changed; increases in wind energy and reductions in hydrogen storage reflect the availability of transmission for synoptic smoothing. This stability is also reflected in Table 3 in the barely-changing marginal prices; the average marginal cost of heating in high density areas in fact remains constant.

In Figure 12 the spatial distribution of primary energy consumption is plotted for the All-Flex-Central scenario with and without optimal transmission. The spatial distribution of technologies remains broadly similar; optimal transmission allows more onshore wind to be build around the North and Baltic Seas, while solar PV is focussed on Southern Europe. Because export is possible with transmission, some countries, such as Ireland, Norway and Sweden where wind resource are good, generate more energy than they consume, while others become net importers.

The $\mathrm{CO}_{2}$ price drops to $407 € / \mathrm{tCO}_{2}$ because the cost of heating is now lower compared to the fuel price. (If heating is the cheapest place to displace $\mathrm{CO}_{2}$, the relationship between the fuel cost $o_{\text {gas }}, \mathrm{CO}_{2}$ price $\mu_{\mathrm{CO} 2}$, specific emissions $\varepsilon_{\text {gas }}$ and heating price $\lambda_{\text {heat }}$ at the cheapest hour and place where gas is consumed is $o_{\text {gas }}+\varepsilon_{\text {gas }} \cdot \mu_{\mathrm{CO} 2}=\lambda_{\text {heat }}$ using the KKT relations.) Note that this price is high enough that other technologies for carbon dioxide reduction that are not in the model, such as carbon capture, might be attractive before this price is reached.

Finally, the reduced marginal costs of space heating would lead to a lower optimal level of building retrofitting than seen, for example, in the Heating scenario. Taking account of the cost of distribution networks and using Figure 5, a reduction in heating demand of around $20-35 \%$ would be efficient in this scenario. Similar levels of optimal retrofitting have also been seen in other studies $[28,36]$.

\subsection{Temporal scales}

The time series of the states of charge of the different storage technologies in the All-Flex-Central scenario without transmission show the different temporal scales on which each storage technology acts (see Figure 13). The methane storage is depleted throughout the winter when energy demand is highest, then replenished throughout the summer with synthetic methane, mirroring seasonal imbalances in demand and renewable supply. (It finishes the year lower than at the start to account for the depletion of natural gas reserves.) The hydrogen storage fluctuates on shorter, synoptic time scales of 2-3 weeks, reflecting its role in balancing wind fluctuations. When spatial smoothing of synoptic variations is possible with the grid, investment in hydrogen storage drops. The long-term hot water storage is dominated by a seasonal pattern similar to that for methane storage superimposed with smaller synoptic variations that match the variations in hydrogen storage. Not plotted are the diurnally-varying storage technologies: the short-term hot water storage that matches the solar thermal collectors, and stationary and vehicular battery storage which follows daily demand and solar PV fluctuations (see Figure 8).

Recognising these different scales is critical to understanding the interaction between demand and renewable generation time series, and thus the resulting system composition. 
Scenario All-Flex-Central with no transmission

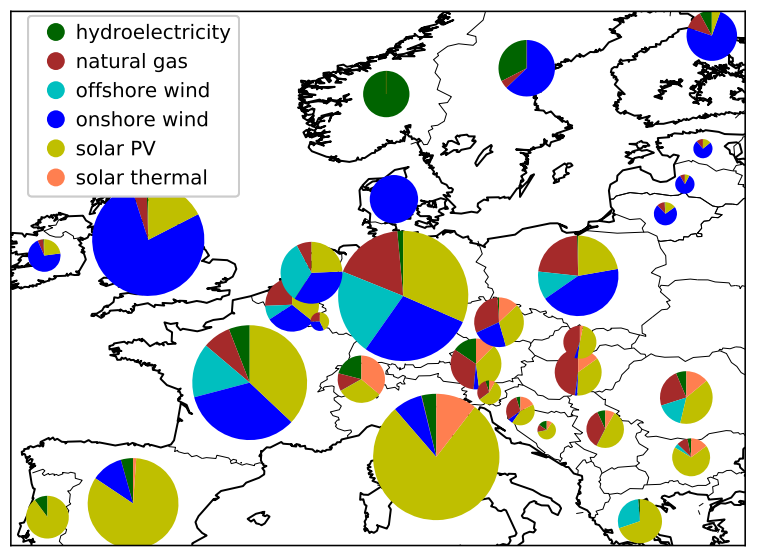

Scenario All-Flex-Central with optimal transmission

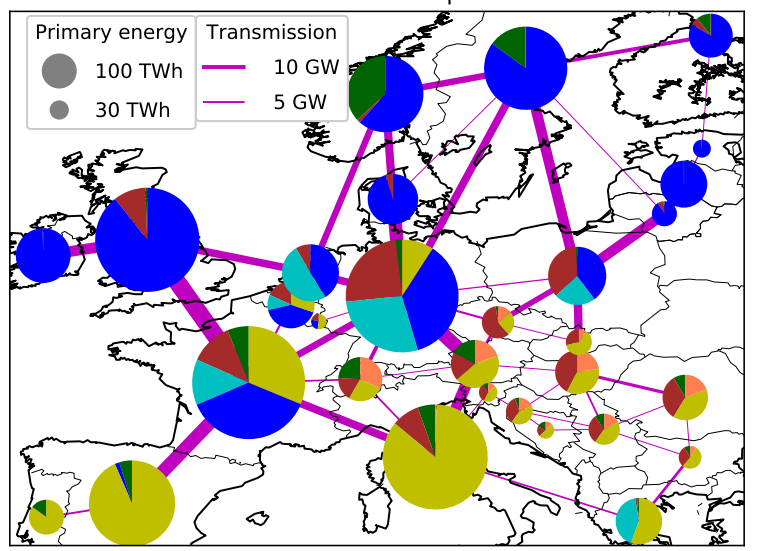

Figure 12: Primary energy consumption in the All-Flex-Central scenario with no transmission (left) and optimal cross-border transmission (right). Given that each country is self-sufficient on the left, the difference in circle size on the right gives an indication of the heterogeneity of energy generation.

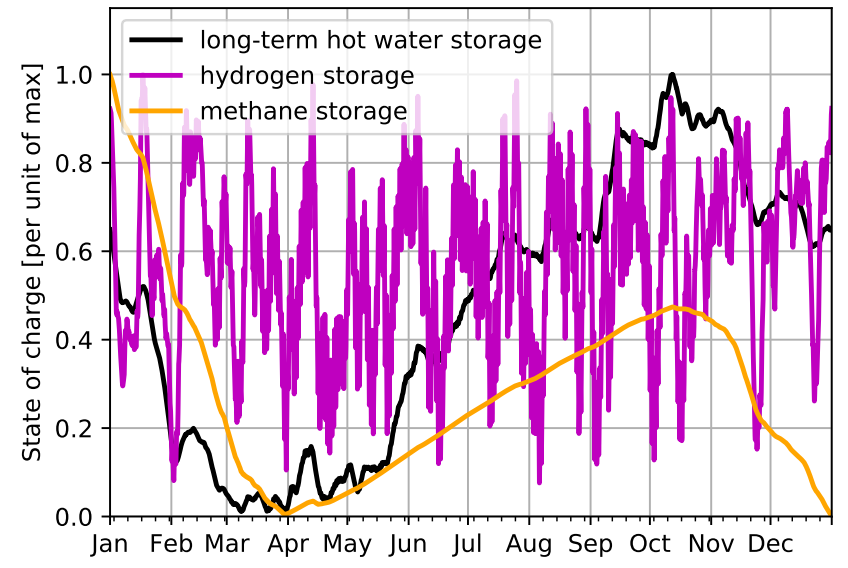

Figure 13: The state of charge for a selection of storage technologies in the AllFlex-Central scenario without transmission, aggregated over all countries, normalised to the total energy capacity (141 TWh for long-term hot water, 9.4 TWh for hydrogen, $806 \mathrm{TWh}$ for methane). Since the state of charge is aggregated, it does not necessarily drop to zero. While the other storage technologies are cyclic over the year, the methane storage finishes the year lower than at the start because of the depletion of natural gas reserves.

\section{Discussion}

\subsection{Comparison of results to today's costs}

To approximate the cost of the current European energy system, some simplifications are made: we assume an average cost of electricity of $50 € / \mathrm{MWh}_{\mathrm{el}}, 8 € / \mathrm{MWh}_{\text {th }}$ for solid fuels, $40 € / \mathrm{MWh}_{\text {th }}$ for oil and $22 € / \mathrm{MWh}_{\text {th }}$ for gas, and assume that all non-electric heat load is met by fossil fuel boilers priced like gas boilers, which are dimensioned to meet the peak thermal load in each country. With these assumptions and energy consumption figures from 2011 [89], costs are 158 billion $€ / a$ for electricity, 203 billion $€ /$ a for fuel in the non-electric heating and transport sectors considered here and 29 billion $€ / a$ for the boilers, resulting in total costs of 390 billion $€ / \mathrm{a}$. The All-Flex-Central scenario with optimal transmission costs just
$13 \%$ more than today's system. Furthermore, the estimation of today's costs excludes the external costs due to greenhouse gases and airborne pollution, estimated by the German Federal Environment Agency (UBA) to be 130 billion $€$ in 2014 in Germany alone [101]. Further analysis of the health effects of air pollution from fossil-fuel-based energy systems can be found in $[102,103]$.

Note that the capital costs for vehicles have not been included in this calculation. Although BEVs are currently more expensive than vehicles with internal combustion engines, the upfront costs are projected to be competitive already by the late 2020 s [104].

\subsection{Comparison of results to other similar studies}

Studies that focus only on the electricity sector typically find that highly renewable systems are dominated by wind, which is most cost-effectively integrated by expanding the pancontinental transmission network [1-5, 7]; without an expansion of the transmission network, solar energy is more favoured, and expensive electricity storage solutions are needed to balance variable renewables [10, 12-14]. The results presented in this study still broadly support these conclusions, but the cost benefit of transmission is weaker with sector-coupling than with electricity alone thanks to the availability of cheap thermal storage, BEV flexibility and power-to-gas facilities, which help to replace much of the expensive stationary electricity storage.

The Smart Energy Europe study [36] uses the modelling tool EnergyPLAN to analyse a scenario with $100 \%$ renewable energy in all sectors in Europe by the year 2050, but with Europe represented as a single node. The technology choices in that study agree with many of the results found in the scenario All-Flex-Central: optimal heat demand savings of 35\%, $80 \%$ electrification of private cars, heat pumps in rural areas, district heating in urban areas and widespread use of synthetic electrofuels. The annual system costs in that study are around 1400 billion $€ /$ a (once the costs of vehicles have been excluded), which is around three times the costs found here. This 
discrepancy is largely due to the stricter renewable energy target and to the inclusion of aviation, shipping and non-electric industrial demand, which greatly increases the costs through the substitution of natural gas, oil and coal with electrofuels. The discrepancy may also be due to a lack of investment optimisation in that study. In the present study, optimisation is used to find the most cost-effective energy system given a fixed $\mathrm{CO}_{2}$ limit. Since [36] assumes perfect transmission within Europe, the present study improves our understanding of the interaction between system characteristics and cross-border transmission bottlenecks.

In [28] a model of the German electricity and heating sectors was optimised to meet a target of $100 \%$ renewable energy. The cost-optimal system ('REMax') sees a broadly similar selection of technologies to the present study: a mix of solar PV, wind onshore and offshore, CHPs, heat pumps, power-to-gas facilities and an optimal level of space heating energy-saving of $31.8 \%$ compared to 2010 values, which agrees with our analysis for the All-Flex-Central scenario. The total annual system costs were 111 billion $€ / a$, which is within the range of our results once the size of Germany's energy demand in relation to Europe's (around one fifth) is taken into account. Nonetheless, that study misses some of the benefits of interconnecting Germany within the European energy system identified here.

The present study also confirms individual results of many other studies: the higher benefit of cross-sector coupling compared to cross-border coupling from the two-country study in [37]; the system benefits of district heating [18, 92, 97, 105]; the benefits of centralised heat storage in district heating networks $[18,106]$; the independence of the benefits of coupling BEV-DSM to the daily cycles of solar PV versus the seasonal storage of energy for the heating sector [93]; the importance of modelling the temperature dependence of the heat pump COP [91]; and the advantages of power-to-gas and methanation in particular in highly renewable energy systems [107].

\subsection{Limitations of the study}

Many of the limitations of this study arise from the simplifications that are necessary to optimise the model in a reasonable amount of time, such as aggregating each country to a single node or reducing the range of available technologies. The impact of these simplifications on the conclusions are now assessed.

Aggregating each country to a single node means that energy distribution networks cannot be represented and that local resource variations are not seen. In this study the costs of district heating and gas distribution networks have been approximated based on their peak loads. On the electrical side, the picture is more complicated, since there is also distributed generation and storage that might either relieve or exacerbate the pressure on distribution networks. Thus, although the costs of interconnecting transmission lines have been taken into account, including the lengths of the inter-connectors inside each country to reach each country's mid-point, it has been assumed that the transmission and distribution networks inside each country will be reinforced to relieve any bottlenecks without attempting to assess the additional costs. The additional costs are typically small compared to the total generation costs (in the range of an addition 10-15\%) based on the results of other studies (see [9] for a review). The grid costs may also be offset by the ability to exploit good wind and solar sites better with a finer-scaled model (see [108] for an examination of these trade-offs). More problematic than the costs is the potential for public concerns about overhead transmission lines to delay or block further grid extension. The costs of ancillary services for the grid have also not been included, since their costs are negligible compared to the total system costs [9]. On the positive side, modelling one node per country accurately reflects the structure of electricity markets in those parts of Europe without zonal pricing.

Constraints in the natural gas transmission network and storage infrastructure are not represented, given that gas consumption in the model is significantly lower than today's gas consumption. (Natural gas consumption in the European Union (EU) was $2890 \mathrm{TWh}$ in 2015 [89] and storage capacity in the EU was 1075 TWh in mid 2017 [109]; total yearly consumption of gas in our model was at most $1500 \mathrm{TWh}$ including synthetic methane.)

Many conservative assumptions regarding technology choices have been made: no biomass has been considered for energy use, given concerns about the sustainability of fuel crops [110] and given that sustainable second-generation biofuels [111] will be needed for the hard-to-defossilise sectors not considered in the model, i.e. process heat in industry and energy-dense fuels for aviation and shipping; the potential to use low-cost second-hand batteries from BEVs as stationary batteries for the grid has been ignored; the use of waste heat from methanation or other industrial processes for electrolysis, direct air capture (DAC) or in district heating networks has been neglected; $\mathrm{CO}_{2}$ for methanation has been conservatively assumed to come from DAC, whereas it would be cheaper to derive it from biogenic sources, power stations or industry; heating directly with hydrogen [112] rather than natural gas was not considered, since it would require a more detailed consideration of changes to delivery infrastructure; carbon capture and storage (CCS) has not been included, although the high prices of $\mathrm{CO}_{2}$ in the model might make it an attractive option; the exploitation of thermal stratification in water tanks, which could improve the efficiency of TES, has been ignored; the efficiency of the natural gas CHP could be improved by using a combined cycle gas turbine for the CHP [113]; although building retrofitting was analysed qualitatively, no further energy efficiency measures were considered, even though these might be desirable beyond the economic optimum in order to reduce the need for energy infrastructure; other synthetic electrofuels for transport, such as methane, dimethyl ether, (m)ethanol or hydrocarbons produced from the Fischer-Tropf process have not been considered, because efficiency losses in their production will be higher than hydrogen and the analysis will be therefore analogous; demand-side management has only been considered for BEV and heat demand, whereas other electric load shifting measures could further decrease the system cost.

A more detailed subdivision of transport demand by vehicle type and usage would allow a more accurate assessment 
of transport technologies, but given the uncertainty around some of the technologies (such as electric roads, overhead pantographs or the distribution of charging points), it may not necessarily be useful. Delineation of each country's building stock would enable a finer analysis of the potential for building retrofitting for energy saving, the thermal inertia of buildings, district heating and the potential for low-temperature heating provision [114].

Upstream emissions from manufacturing renewable generators have not been considered, although these are small (the energy required for manufacture as a fraction of lifetime energy generation is just $2.3 \%$ for wind and $3.8 \%$ for PV [115]); on the other hand, it was recently estimated that $12.6 \%$ of all end-use energy worldwide is used to mine, transport and refine fossil fuels and uranium [116]. These concerns can be addressed once all non-electric industrial demand is included in the model.

On the modelling side, only a single historical weather year (2011) has been modelled with perfect foresight, which may mean the model is over-tuned to this year and ignores the future effects of global warming. In an upcoming paper [117] by some of the authors, the sensitivity of the electricity-only model from [13] to different years or multiple years was examined and found to be negligible; a similar low sensitivity to the year was found in the sector-coupled model of most of Europe in [52] based on 7 historical weather years. [117] also analyses the sensitivity of the model to changing cost assumptions for generation and storage, wherein some sensitivity is seen to the ratio of solar PV to wind costs.

Finally the availability of the model online [47, 48] facilitates further analysis and experimentation by other researchers.

\section{Conclusions}

In this paper the model PyPSA-Eur-Sec-30 has been presented. PyPSA-Eur-Sec-30 is the first open, spatially-resolved, temporally-resolved and sector-coupled energy model covering the whole of Europe. The coupling of the heating and transport sectors to electricity in a European context enables both the consideration of a higher share $(75 \%)$ of the total final energy usage in the model and an assessment of the benefits of cross-border transmission versus enhanced flexibility from sector-coupling in highly renewable scenarios.

In scenarios where $\mathrm{CO}_{2}$ emissions are reduced by $95 \%$ compared to 1990 levels, the cost-optimal use of battery electric vehicles, synthetic electrofuels, heat pumps, district heating and long-term thermal energy storage removes the economic case for almost all stationary electricity storage and can reduce total system costs by up to $28 \%$. These flexibility options work on different time scales (diurnal, synoptic and seasonal) to help balance the variability of demand and that of solar and wind generation, which provide the bulk of primary energy in these scenarios and comprise the majority of the system costs.

The cost benefit of these flexibility options (28\%) is greater than the benefit of cross-border transmission on its own (25\%). Transmission helps to smooth renewables, particularly wind, in space across the continent, rather than in time. However, if used together, sector-coupling flexibility and transmission can reduce total system costs by $37 \%$ compared to a scenario with no inter-connection and inflexible sector-coupling. This leads to scenarios with $95 \%$ lower emissions that are only marginally more expensive than today's energy system. If the damage from greenhouse gas emissions and air pollution is taken into account, the highly renewable systems presented here are of considerable benefit to society compared to today's system.

Based on the results of this study, the following policy conclusions can be drawn: in cost-optimal energy systems with low emissions, wind and solar dominate primary energy generation, while heat pumps dominate heat provision; increasing crossborder transmission capacity by a few multiples of today's capacity, particularly around the North and Baltic Seas, is robustly cost-efficient across a wide range of scenarios; electrification of transport is more cost-effective than using synthetic fuels in transport because of efficiency losses when producing the fuels; the algorithms for managing battery electric vehicle charging should be exposed to dynamic electricity market prices; district heating in high-density, urban areas with long-term thermal energy storage can significantly reduce costs (as long as it is carefully regulated in view of the potential for monopoly exploitation); for heating individual buildings in rural areas, heating systems with multiple technologies (heat pumps, resistive heating, solar thermal collectors and backup gas boilers for cold periods) can be efficient; converting power to hydrogen and methane is advantageous in highly renewable systems, and the technologies for methanation and carbon dioxide capture should be developed further in view of this; finally, there are a variety of different possible paths to a highly renewable energy system, and no significant technical or economic barriers could be identified.

\section{Acknowledgments}

The authors thank Gorm Andresen, Tobias Bischof-Niemz, Christian Breyer, Tom Brown Senior, Magnus Dahl, Thomas Grube, Veit Hagenmeyer, Heidi Heinrichs, Jonas Hörsch, Robbie Morrison, Andreas Palzer, Marta Victoria Pérez, Martin Robinius, Mirko Schäfer and Kun Zhu for helpful discussions and suggestions. This research was conducted as part of the CoNDyNet project, which was supported by the German Federal Ministry of Education and Research under grant number 03SF0472C. T.B. and M.G. were partially funded by the REINVEST project, which is supported by the Innovation Fund Denmark under grant number 6154-00022B. T.B. also acknowledges funding from the Helmholtz Association under grant no. VH-NG-1352. The responsibility for the contents lies solely with the authors.

\section{References}

[1] G. Czisch, Szenarien zur zukünftigen Stromversorgung, Ph.D. thesis, Universität Kassel (2005).

[2] Schaber, K., Steinke, F., Hamacher, T., Transmission grid extensions for the integration of variable renewable energies in Europe: Who benefits where?, Energy Policy 43 (2012) 123 - 135. doi:10.1016/j.enpol. 
2011.12 .040 .

URL https : //doi .org/10.1016/j .enpol .2011.12.040

[3] Schaber, K., Steinke, F., Mühlich, P., Hamacher, T., Parametric study of variable renewable energy integration in Europe: Advantages and costs of transmission grid extensions, Energy Policy 42 (2012) 498-508. doi : 10.1016/j.enpol.2011.12.016. URL https: //doi .org/10.1016/j.enpol.2011.12.016

[4] Y. Scholz, Renewable energy based electricity supply at low costs - Development of the REMix model and application for Europe, Ph.D. thesis, Universität Stuttgart (2012).

URL https : //doi .org/10.18419/opus-2015

[5] Rodriguez, R.A., Becker, S., Andresen, G., Heide, D., Greiner, M., Transmission needs across a fully renewable European power system, Renewable Energy 63 (2014) 467-476. doi:10.1016/j.renene. 2013.10.005.

URL https://doi.org/10.1016/j.renene.2013.10.005

[6] C. Bussar, M. Moos, R. Alvarez, P. Wolf, T. Thien, H. Chen, Z. Cai, M. Leuthold, D. U. Sauer, A. Moser, Optimal Allocation and Capacity of Energy Storage Systems in a Future European Power System with 100\% Renewable Energy Generation, Energy Procedia 46 (2014) 40 47, 8th International Renewable Energy Storage Conference and Exhibition (IRES 2013). doi:10.1016/j.egypro.2014.01.156.

[7] E. H. Eriksen, L. J. Schwenk-Nebbe, B. Tranberg, T. Brown, M. Greiner, Optimal heterogeneity in a simplified highly renewable European electricity system, Energy 133 (Supplement C) (2017) 913 - 928. doi : 10.1016/j . energy.2017.05.170.

URL https://doi.org/10.1016/j.energy . 2017.05.170

[8] C. Breyer, D. Bogdanov, A. Aghahosseini, A. Gulagi, M. Child, A. S Oyewo, J. Farfan, K. Sadovskaia, P. Vainikka, Solar photovoltaics demand for the global energy transition in the power sector, Progress in Photovoltaics: Research and Applications (2017) n/a-n/aPIP-17137.R1. doi:10.1002/pip. 2950.

URL http://dx.doi.org/10.1002/pip. 2950

[9] T. Brown, T. Bischof-Niemz, K. Blok, C. Breyer, H. Lund, B. Mathiesen, Response to 'burden of proof: A comprehensive review of the feasibility of $100 \%$ renewable-electricity systems', Renewable and Sustainable Energy Reviews 92 (2018) 834 - 847. doi : 10.1016/j.rser . 2018.04 .113$.

URL https ://doi.org/10.1016/j.rser.2018.04.113

[10] M. Haller, S. Ludig, N. Bauer, Decarbonization scenarios for the EU and MENA power system: Considering spatial distribution and short term dynamics of renewable generation, Energy Policy 47 (2012) 282 290. doi:10.1016/j.enpol.2012.04.069.

URL https : //doi .org/10.1016/j.enpol.2012.04.069

[11] S. Hagspiel, C. Jägemann, D. Lindenburger, T. Brown, S. Cherevatskiy, E. Tröster, Cost-optimal power system extension under flow-based market coupling, Energy 66 (2014) 654-666. doi:10.1016/j.energy . 2014.01 .025$.

URL https : //doi .org/10.1016/j.energy.2014.01.025

[12] H. C. Gils, Y. Scholz, T. Pregger, D. L. de Tena, D. Heide, Integrated modelling of variable renewable energy-based power supply in Europe, Energy 123 (2017) 173 - 188. doi:https://doi.org/10.1016/j . energy.2017.01.115.

URL $10.1016 / j$. energy . 2017.01.115

[13] D. Schlachtberger, T. Brown, S. Schramm, M. Greiner, The benefits of cooperation in a highly renewable European electricity network, Energy 134 (2017) 469 - 481. doi : 10.1016/j . energy . 2017.06.004. URL https://doi.org/10.1016/j.energy.2017.06.004

[14] F. Cebulla, T. Naegler, M. Pohl, Electrical energy storage in highly renewable European energy systems: Capacity requirements, spatial distribution, and storage dispatch, Journal of Energy Storage 14 (Part 1) (2017) $211-223$. doi:10.1016/j.est. 2017.10.004. URL https://doi.org/10.1016/j.est.2017.10.004

[15] H. Lund, P. A. Østergaard, D. Connolly, B. V. Mathiesen, Smart energy and smart energy systems, Energy 137 (Supplement C) (2017) 556 565. doi:10.1016/j.energy.2017.05.123.

URL https : //doi.org/10.1016/j.energy. 2017.05.123

[16] H. Lund (Ed.), The Choice and Modelling of $100 \%$ Renewable Solutions, Academic Press, 2010.

[17] P. Meibom, J. Kiviluoma, R. Barth, H. Brand, C. Weber, H. V. Larsen, Value of electric heat boilers and heat pumps for wind power integration,
Wind Energy 10 (4) (2007) 321-337. doi : 10.1002/we. 224

URL http://dx.doi.org/10.1002/we.224

[18] A. Pensini, C. N. Rasmussen, W. Kempton, Economic analysis of using excess renewable electricity to displace heating fuels, Applied Energy 131 (Supplement C) (2014) 530 - 543. doi : 10.1016/j . apenergy . 2014.04 .111$.

URL https ://doi.org/10.1016/j . apenergy . 2014.04.111

[19] A. Ashfaq, Z. H. Kamali, M. H. Agha, H. Arshid, Heat coupling of the pan-European vs. regional electrical grid with excess renewable energy, Energy 122 (Supplement C) (2017) 363 - 377. doi : 10.1016/j . energy.2017.01.084.

URL https : //doi.org/10.1016/j.energy . 2017.01.084

[20] W. Kempton, S. E. Letendre, Electric vehicles as a new power source for electric utilities, Transportation Research Part D: Transport and Environment 2 (3) (1997) 157 - 175. doi:10.1016/S1361-9209(97) $00001-1$

URL https : //doi.org/10.1016/S1361-9209(97)00001-1

[21] J. Kiviluoma, P. Meibom, Methodology for modelling plug-in electric vehicles in the power system and cost estimates for a system with either smart or dumb electric vehicles, Energy 36 (3) (2011) 1758-1767. doi : 10.1016/j.energy.2010.12.053.

URL https : //doi.org/10.1016/j.energy . 2010.12.053

[22] W.-P. Schill, C. Gerbaulet, Power system impacts of electric vehicles in Germany: Charging with coal or renewables?, Applied Energy 156 (2015) 185 - 196. doi : 10.1016/j . apenergy.2015.07.012. URL https ://doi.org/10.1016/j.apenergy.2015.07.012

[23] M. Robinius, A. Otto, P. Heuser, L. Welder, K. Syranidis, D. S. Ryberg, T. Grube, P. Markewitz, R. Peters, D. Stolten, Linking the Power and Transport Sectors-Part 1: The Principle of Sector Coupling, Energies 10 (7). doi : 10.3390/en10070956. URL https://doi.org/10.3390/en10070956

[24] M. Robinius, A. Otto, K. Syranidis, D. S. Ryberg, P. Heuser, L. Welder, T. Grube, P. Markewitz, V. Tietze, D. Stolten, Linking the Power and Transport Sectors-Part 2: Modelling a Sector Coupling Scenario for Germany, Energies 10 (7). doi:10.3390/en10070957.

URL http://doi .org/10.3390/en10070957

[25] S. Schiebahn, T. Grube, M. Robinius, V. Tietze, B. Kumar, D. Stolten, Power to gas: Technological overview, systems analysis and economic assessment for a case study in Germany, International Journal of Hydrogen Energy 40 (12) (2015) 4285 - 4294. doi : 10.1016/j . i jhydene. 2015.01 .123

URL https : //doi.org/10.1016/j.ijhydene.2015.01.123

[26] M. Robinius, T. Raje, S. Nykamp, T. Rott, M. Müller, T. Grube, B. Katzenbach, S. Küppers, D. Stolten, Power-to-Gas: Electrolyzers as an alternative to network expansion - An example from a distribution system operator, Applied Energy 210 (2018) 182 - 197. doi: 10.1016/j . apenergy .2017.10.117. URL https : //doi.org/10.1016/j . apenergy . 2017.10.117

[27] H.-M. Henning, A. Palzer, A comprehensive model for the German electricity and heat sector in a future energy system with a dominant contribution from renewable energy technologies-Part I: Methodology, Renewable and Sustainable Energy Reviews 30 (2014) 1003 - 1018. URL https : //doi.org/10.1016/j.rser.2013.09.012

[28] A. Palzer, H.-M. Henning, A comprehensive model for the German electricity and heat sector in a future energy system with a dominant contribution from renewable energy technologies - Part II: Results, Renewable and Sustainable Energy Reviews 30 (Supplement C) (2014) 1019 1034. doi:10.1016/j.rser.2013.11.032. URL https : //doi.org/10.1016/j.rser.2013.11.032

[29] N. Gerhardt, A. Scholz, F. Sandau, H. Hahn, Interaktion EE-Strom, Wärme und Verkehr, Tech. rep., Fraunhofer IWES (2015). URL http://www.energiesystemtechnik.iwes.fraunhofer.

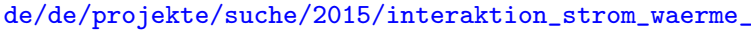
verkehr.html

[30] V. Quaschning, Sektorkopplung durch die Energiewende, Tech. rep., HTW Berlin (2016).

[31] H. Lund, B. Mathiesen, Energy system analysis of $100 \%$ renewable energy systems - The case of Denmark in years 2030 and 2050, Energy 34 (5) (2009) 524 - 531, 4th Dubrovnik Conference. doi : 10.1016/j . energy.2008.04.003. URL https : //doi.org/10.1016/j.energy.2008.04.003 
[32] B. V. Mathiesen, H. Lund, D. Conolly, H. Wenzel, P. Østergaard, B. Möller, S. Nielsen, I. Ridjan, P. Karnøe, K. Sperling, F. Hvelplund, Smart energy systems for coherent $100 \%$ renewable energy and transport solutions, Applied Energy 145 (2015) 139-154. doi : 10.1016/j. apenergy.2015.01.075.

URL https://doi.org/10.1016/j .apenergy. 2015.01.075

[33] H. Lund, A. N. Andersen, P. A. Østergaard, B. V. Mathiesen, D. Connolly, From electricity smart grids to smart energy systems - a market operation based approach and understanding, Energy 42 (1) (2012) 96 - 102, 8th World Energy System Conference, WESC 2010. doi : $10.1016 / j$. energy .2012 .04 .003 URL https://doi.org/10.1016/j.energy.2012.04.003

[34] D. Connolly, H. Lund, B. Mathiesen, M. Leahy, The first step towards a 100\% renewable energy-system for Ireland, Applied Energy 88 (2) (2011) 502 - 507, the 5th Dubrovnik Conference on Sustainable Development of Energy, Water and Environment Systems, held in Dubrovnik September/October 2009. doi:10.1016/j . apenergy. 2010.03 .006

URL https://doi.org/10.1016/j. apenergy.2010.03.006

[35] J. Deane, A. Chiodi, M. Gargiulo, B. P. O. Gallachoir, Soft-linking of a power systems model to an energy systems model, Energy 42 (1) (2012) $303-312$, 8th World Energy System Conference, \{WESC 2010. doi : $10.1016 / j$. energy. 2012.03.052. URL https://doi.org/10.1016/j.energy.2012.03.052

[36] D. Connolly, H. Lund, B. Mathiesen, Smart Energy Europe: The technical and economic impact of one potential 100\% renewable energy scenario for the European Union, Renewable and Sustainable Energy Reviews 60 (2016) 1634 - 1653. doi:10.1016/j.rser.2016.02.025. URL https://doi.org/10.1016/j.rser.2016.02.025

[37] J. Z. Thellufsen, H. Lund, Cross-border versus cross-sector interconnectivity in renewable energy systems, Energy 124 (Supplement C) (2017) 492 - 501. doi:10.1016/j.energy . 2017.02.112. URL https://doi.org/10.1016/j.energy.2017.02.112

[38] The PRIMES Model, Tech. rep., NTUA (2009).

[39] M. Leimbach, N. Bauer, L. Baumstark, M. Luken, O. Edenhofer, Technological Change and International Trade - Insights from REMIND-R, The Energy Journal 31. doi: 10.5547/ISSN0195-6574-EJ-Vol31-NoSI-5. URL https: //doi .org/10.5547/ISSN0195-6574-EJ-Vol31-NoSI-5

[40] P. Capros, L. Paroussos, P. Fragkos, S. Tsani, B. Boitier, F. Wagner, S. Busch, G. Resch, M. Blesl, J. Bollen, European decarbonisation pathways under alternative technological and policy choices: A multi-model analysis, Energy Strategy Reviews 2 (3) (2014) 231 - 245, sustainable Energy System Changes. doi:10.1016/j.esr.2013.12.007. URL https://doi.org/10.1016/j.esr. 2013.12.007

[41] S. Simoes, W. Nijs, P. Ruiz, A. Sgobbi, C. Thiel, Comparing policy routes for low-carbon power technology deployment in EU - an energy system analysis, Energy Policy 101 (2017) 353 - 365. doi :10.1016/ j.enpol.2016.10.006. URL https://doi.org/10.1016/j.enpol.2016.10.006

[42] K. Löffler, K. Hainsch, T. Burandt, P.-Y. Oei, C. Kemfert, C. von Hirschhausen, Designing a Model for the Global Energy System-GENeSYS-MOD: An Application of the Open-Source Energy Modeling System (OSeMOSYS), Energies 10 (10). doi:10.3390/ en10101468.

URL https://doi.org/10.3390/en10101468

[43] S. Ludig, M. Haller, E. Schmid, N. Bauer, Fluctuating renewables in a long-term climate change mitigation strategy, Energy 36 (11) (2011) 6674 - 6685. doi:10.1016/j.energy. 2011.08.021. URL https://doi.org/10.1016/j.energy.2011.08.021

[44] L. Kotzur, P. Markewitz, M. Robinius, D. Stolten, Impact of different time series aggregation methods on optimal energy system design, Renewable Energy 117 (2018) 474 - 487. doi:10.1016/j.renene. 2017.10 .017$.

URL https://doi.org/10.1016/j.renene.2017.10.017

[45] European Council, Presidency Conclusions of Meeting of European Council on 29/30 October 2009, http://www. consilium. europa. eu/uedocs/cms_data/docs/pressdata/en/ec/110889.pdf, Online, retrieved August 2016 (2009).

[46] Kyoto Protocol: Reference Manual, Tech. rep., United Nations Framework Convention on Climate Change (2008).
[47] T. Brown, D. Schlachtberger, Supplementary Data: Code, Input Data and Result Summaries: Synergies of sector coupling and transmission extension in a cost-optimised, highly renewable European energy system (2018). doi:10.5281/zenodo.1146665.

URL https://doi.org/10.5281/zenodo. 1146665

[48] T. Brown, D. Schlachtberger, Supplementary Data: Full Results: Synergies of sector coupling and transmission extension in a cost-optimised, highly renewable European energy system (2018). doi:10.5281/ zenodo. 1146649

URL https://doi .org/10.5281/zenodo. 1146649

[49] S. Pfenninger, J. DeCarolis, L. Hirth, S. Quoilin, I. Staffell, The importance of open data and software: Is energy research lagging behind?, Energy Policy 101 (2017) 211 -215. doi:10.1016/j .enpol. 2016. 11.046.

URL https://doi.org/10.1016/j.enpol.2016.11.046

[50] S. Pfenninger, L. Hirth, I. Schlecht, E. Schmid, F. Wiese, T. Brown, C. Davis, M. Gidden, H. Heinrichs, C. Heuberger, S. Hilpert, U. Krien, C. Matke, A. Nebel, R. Morrison, B. Müller, G. Pleßmann, M. Reeg, J. C. Richstein, A. Shivakumar, I. Staffell, T. Tröndle, C. Wingenbach, Opening the black box of energy modelling: Strategies and lessons learned, Energy Strategy Reviews 19 (2018) 63 - 71. doi:10.1016/ j.esr.2017.12.002.

URL https://doi.org/10.1016/j.esr.2017.12.002

[51] T. Brown, J. Hörsch, D. Schlachtberger, PyPSA: Python for Power System Analysis, Journal of Open Research Software 6 (4). arXiv: 1707.09913, doi:10.5334/jors. 188 . URL https://doi.org/10.5334/jors. 188

[52] N. Gerhardt, D. Böttger, T. Trost, A. Scholz, C. Pape, A.-K. Gerlach, P. Härtel, I. Ganal, Analyse eines europäischen 95\%-Klimazielszenarios über mehrere Wetterjahre, Tech. rep., Fraunhofer IWES (2017).

URL http://www.energieversorgung-elektromobilitaet. de/includes/reports/Auswertung_7Wetterjahre_95Prozent_ FraunhoferIWES.pdf

[53] Gurobi Optimization Inc., Gurobi optimizer reference manual (2017). URL http://www . gurobi.com

[54] A. Schröder, F. Kunz, J. Meiss, R. Mendelevitch, C. von Hirschhausen, Current and prospective costs of electricity generation until 2050, Data Documentation, DIW 68, Deutsches Institut für Wirtschaftsforschung (DIW), Berlin (2013).

URL http://hdl . handle.net/10419/80348

[55] E. Vartiainen, G. Masson, C. Breyer, The True Competitiveness of Solar PV: A European Case Study, Tech. rep., European Technology and Innovation Platform for Photovoltaics (2017).

URL http://www.etip-pv.eu/fileadmin/Documents/ETIP_ PV_Publications_2017-2018/LCOE_Report_March_2017.pdf

[56] Technology data for generation of electricity and district heating, energy storage and energy carrier generation and conversion, Tech. rep., Danish Energy Agency and Energinet.dk (2016).

URL https://ens.dk/en/our-services/ projections-and-models/technology-data

[57] C. Budischak, D. Sewell, H. Thomson, L. Mach, D. E. Veron, W. Kempton, Cost-minimized combinations of wind power, solar power and electrochemical storage, powering the grid up to $99.9 \%$ of the time, Journal of Power Sources 225 (2013) $60-74$. doi:10.1016/j.jpowsour. 2012.09.054.

URL https://doi.org/10.1016/j.jpowsour. 2012.09.054

[58] A. Palzer, Sektorübergreifende Modellierung und Optimierung eines zukünftigen deutschen Energiesystems unter Berücksichtigung von Energieeffizienzmaßnahmen im Gebäudesektor, Ph.D. thesis, KIT (2016).

[59] D. M. Steward, Scenario development and analysis of hydrogen as a large-scale energy storage medium, Tech. rep. (2009).

[60] M. Fasihi, D. Bogdanov, C. Breyer, Long-Term Hydrocarbon Trade Options for the Maghreb Region and Europe-Renewable Energy Based Synthetic Fuels for a Net Zero Emissions World, Sustainability 9 (2). doi:10.3390/su9020306. URL https://doi .org/10.3390/su9020306

[61] K. Schaber, Integration of Variable Renewable Energies in the European power system: a model-based analysis of transmission grid extensions and energy sector coupling, Ph.D. thesis, TU München (2013).

[62] Monitoringbericht 2017, Tech. rep., Bundesnetzagentur (2017). URL https://www.bundesnetzagentur.de/DE/ 
Sachgebiete/ElektrizitaetundGas/Unternehmen_

Institutionen/DatenaustauschundMonitoring/Monitoring/ Monitoringberichte/Monitoring_Berichte.html

[63] B. Zakeri, S. Syri, Electrical energy storage systems: A comparative life cycle cost analysis, Renewable and Sustainable Energy Reviews 42 (Supplement C) (2015) 569 - 596. doi:10.1016/j.rser. 2014. 10.011

URL https ://doi.org/10.1016/j.rser.2014.10.011

[64] P. Elsner, D. U. Sauer, Energiespeicher: Technologiesteckbrief zur Analyse „Flexibilitätskonzepte für die Stromversorgung 2050“, Tech. rep. (2015).

URL http://www.acatech.de/fileadmin/user_upload/ Baumstruktur_nach_Website/Acatech/root/de/

Publikationen/Materialien/ESYS_Technologiesteckbrief Energiespeicher.pdf

[65] J. Hörsch, F. Hofmann, D. Schlachtberger, T. Brown, PyPSA-Eur: An Open Optimisation Model of the European Transmission System. URL https: //arxiv .org/abs/1806.01613

[66] Open Power System Data, Data Package Time series. Version 2017 07-09, https://data.open-power-system-data.org/time_ series/2017-07-09/ (July 2017).

[67] European Transmission System Operators, Country-specific hourly load data, https://www.entsoe.eu/data/data-portal/ consumption/ (2011).

[68] G. B. Andresen, A. A. Søndergaard, M. Greiner, Validation of Danish wind time series from a new global renewable energy atlas for energy system analysis, Energy 93, Part 1 (2015) 1074 - 1088. doi : 10.1016/ j.energy.2015.09.071.

URL https://doi.org/10.1016/j . energy . 2015.09.071

[69] S. Saha, et al., The NCEP Climate Forecast System Reanalysis, Bulletin of the American Meteorological Society 91 (8) (2010) 1015-1057. doi : 10.1175/2010BAMS3001.1.

[70] S. Pfenninger, I. Staffell, Long-term patterns of European PV output using 30 years of validated hourly reanalysis and satellite data, Energy 114 (Supplement C) (2016) 1251 - 1265. doi:10.1016/j.energy . 2016.08 .060 .

URL https : //doi.org/10.1016/j.energy. 2016.08.060

[71] R. Müller, U. Pfeifroth, C. Träger-Chatterjee, J. Trentmann, R. Cremer, Digging the meteosat treasure-3 decades of solar surface radiation, Remote Sensing 7 (6) (2015) 8067-8101. doi :10.3390/rs70608067. URL https : //doi .org/10.3390/rs70608067

[72] EEA, Natura 2000 data - the European network of protected sites, http: //www . eea. europa. eu/data-and-maps/data/natura-7 (2016).

[73] EEA, Corine land cover 2006 (2014).

[74] Kies, A., Chattopadhyay, K., von Bremen, L., Lorenz, E., Heinemann, D., RESTORE 2050 Work Package Report D12: Simulation of renewable feed-in for power system studies., Tech. rep., RESTORE 2050, in preparation (2016).

[75] B. Pfluger, F. Sensfuß, G. Schubert, J. Leisentritt, Tangible ways towards climate protection in the European Union (EU Long-term scenarios 2050), Fraunhofer ISI.

[76] Installed Capacity per Production Type in 2015, Tech. rep., ENTSO-E (2016).

[77] Verkehrszählung - Stundenwerte, Tech. rep., Bundesanstalt für Straßenwesen.

[78] ODYSSEE database on energy efficiency data \& indicators, Tech. rep., Enerdata (2016)

[79] US Environmental Protection Agency, 2017 Car Fuel Economy Estimates, https: //www . fueleconomy.gov/feg/ (2017).

[80] Tesla model s range estimator (2017). URL https : //www.tesla.com/models

[81] D. Connolly, Economic viability of electric roads compared to oil and batteries for all forms of road transport, Energy Strategy Reviews 18 (Supplement C) (2017) 235 - 249. doi:10.1016/j.esr. 2017. 09.005

URL https: //doi.org/10.1016/j.esr.2017.09.005

[82] H. Lund, W. Kempton, Integration of renewable energy into the transport and electricity sectors through V2G, Energy Policy 36 (9) (2008) 3578 - 3587. doi:10.1016/j .enpol.2008.06.007.

URL https://doi.org/10.1016/j.enpol.2008.06.007

[83] W. Kempton, J. Tomić, S. Letendre, A. Brooks, T. Lipman, Vehicle-to-
Grid Power: Battery, Hybrid, and Fuel Cell Vehicles as Resources for Distributed Electric Power in California, Tech. rep. (2001).

URL http: //www1.udel.edu/V2G/docs/V2G-Cal-2001.pdf

[84] T. Markel, K. Bennion, W. Kramer, J. Bryan, J. Giedd, Field Testing Plug-in Hybrid Electric Vehicles with Charge Control Technology in the Xcel Energy Territory, Tech. rep., NREL (2009).

URL http://citeseerx.ist.psu.edu/viewdoc/download? doi=10.1.1.504.1653\&rep=rep1\&type=pdf

[85] M. D. Galus, M. G. Vayá, T. Krause, G. Andersson, The role of electric vehicles in smart grids, Wiley Interdisciplinary Reviews: Energy and Environment 2 (4) (2013) 384-400. doi : 10.1002/wene.56 URL https : //doi.org/10.1002/wene. 56

[86] J. Walker, C. Johnson, Peak car ownership: The market opportunity of electric automated mobility services, Tech. rep., Rocky Mountain Institute (2016).

URL http: //www.rmi.org/peak_car_ownership

[87] A. R. Jensen, Coupling of a highly renewable electricity system to the heating sector, Master's thesis, Aarhus University (2016).

[88] A. Ashfaq, A. Ianakiev, Cost-minimised design of a highly renewable heating network for fossil-free future, Energy 152 (2018) 613 - 626. doi: 10.1016/j.energy.2018.03.155.

URL https : //doi.org/10.1016/j . energy . 2018.03.155

[89] Energy Balances 1900 - 2014, Tech. rep., Eurostat (2016).

[90] Analyse des schweizerischen Energieverbrauchs 2000-2016 nach Verwendungszwecken, Tech. rep., Swiss Federal Office of Energy (2017). URL http://www.bfe.admin.ch/themen/00526/00541/00542/ $02167 /$ index.html?dossier_id=02169

[91] S. N. Petrović, K. B. Karlsson, Residential heat pumps in the future Danish energy system, Energy 114 (Supplement C) (2016) 787 - 797. doi:10.1016/j.energy.2016.08.007.

URL https : //doi.org/10.1016/j.energy.2016.08.007

[92] U. Persson, S. Werner, Heat distribution and the future competitiveness of district heating, Applied Energy 88 (3) (2011) 568 - 576. doi : 10 . 1016/j. apenergy . 2010.09.020. URL https : //doi.org/10.1016/j . apenergy.2010.09.020

[93] H. C. Gils, Balancing of intermittent renewable power generation by demand response and thermal energy storage, Ph.D. thesis, University of Stuttgart (2015).

[94] Heat Roadmap Europe, Tech. rep. (2016).

[95] I. Staffell, D. Brett, N. Brandon, A. Hawkes, A review of domestic heat pumps, Energy Environ. Sci. 5 (2012) 9291-9306. doi : 10.1039/ C2EE22653G.

URL https : //doi.org/10.1039/C2EE22653G

[96] P. E. Grohnheit, Modelling CHP within a national power system, Energy Policy 21 (4) (1993) 418 - 429. doi : 10.1016/0301-4215(93) 90282-K.

URL https : //doi .org/10.1016/0301-4215(93)90282-K

[97] D. Connolly, H. Lund, B. Mathiesen, S. Werner, B. Möller, U. Persson, T. Boermans, D. Trier, P. Østergaard, S. Nielsen, Heat Roadmap Europe: Combining district heating with heat savings to decarbonise the EU energy system, Energy Policy 65 (Supplement C) (2014) 475 - 489. doi:https://doi.org/10.1016/j.enpol.2013.10.035. URL $10.1016 / j$.enpol .2013 .10 .035

[98] D. Connolly, EnergyPLAN Cost Database 3.0, Tech. rep. (2015). URL http: //www . energyplan.eu/costdatabase/

[99] ACER, ACER Market Monitoring Report 2016, Tech. rep. (2017). URL http://www.acer.europa.eu/Official_documents/ Acts_of_the_Agency/Publication/ACER\%20Market $\%$ 20Monitoring\%20Report $\% 202016 \% 20$ - \%20ELECTRICITY .pdf

[100] European Network of Transmission System Operators for Electricity, Ten-Year Network Development Plan (TYNDP) 2016, Tech. rep., ENTSO-E (2016)

URL http: //tyndp.entsoe.eu/

[101] Indikator: Umweltkosten von Energie und Straßenverkehr (2017). URL https://www.umweltbundesamt.de/ indikator-umweltkosten-von-energie-strassenverkehr

[102] Delucchi, M.A., Jacobson, M.Z., Providing all global energy with wind, water, and solar power, Part II: Reliability, system and transmission costs, and policies, Energy Policy 39 (3) (2011) 1170-1190. doi : 10.1016/j.enpol.2010.11.045. URL https: //doi.org/10.1016/j.enpol.2010.11.045 
[103] E. Zvingilaite, Human health-related externalities in energy system modelling the case of the Danish heat and power sector, Applied Energy 88 (2) (2011) 535 - 544, the 5th Dubrovnik Conference on Sustainable Development of Energy, Water and Environment Systems, held in Dubrovnik September/October 2009. doi : 10.1016/j . apenergy . 2010.08 .007$.

URL https : //doi.org/10.1016/j.apenergy . 2010.08.007

[104] Electric vehicle outlook 2018, Tech. rep., Bloomberg New Energy Finance (2018).

[105] M. Münster, P. E. Morthorst, H. V. Larsen, L. Bregnbæk, J. Werling, H. H. Lindboe, H. Ravn, The role of district heating in the future Danish energy system, Energy 48 (1) (2012) 47 - 55, 6th Dubrovnik Conference on Sustainable Development of Energy Water and Environmental Systems, SDEWES 2011. doi : 10.1016/j . energy . 2012.06.011. URL https : //doi.org/10.1016/j.energy.2012.06.011

[106] T. Nuytten, B. Claessens, K. Paredis, J. V. Bael, D. Six, Flexibility of a combined heat and power system with thermal energy storage for district heating, Applied Energy 104 (Supplement C) (2013) 583 - 591. doi : 10.1016/j.apenergy.2012.11.029.

URL https : //doi .org/10.1016/j . apenergy.2012.11.029

[107] M. Sterner, Bioenergy and renewable power methane in integrated $100 \%$ renewable energy systems, Ph.D. thesis, Kassel University (2009). URL http://www.upress.uni-kassel.de/katalog/abstract. php?978-3-89958-798-2

[108] J. Hörsch, T. Brown, The role of spatial scale in joint optimisations of generation and transmission for European highly renewable scenarios, in: Proceedings of 14th International Conference on the European Energy Market (EEM 2017), 2017. doi :10.1109/EEM . 2017.7982024. URL https : //arxiv.org/abs/1705.07617

[109] G. I. Europe, Gas storage data, https://agsi.gie.eu/, https:// agsi.gie.eu/.

[110] F. Creutzig, N. H. Ravindranath, G. Berndes, S. Bolwig, R. Bright, F. Cherubini, H. Chum, E. Corbera, M. Delucchi, A. Faaij, J. Fargione, H. Haberl, G. Heath, O. Lucon, R. Plevin, A. Popp, C. Robledo-Abad, S. Rose, P. Smith, A. Stromman, S. Suh, O. Masera, Bioenergy and climate change mitigation: an assessment, GCB Bioenergy 7 (5) (2015) 916-944. doi:10.1111/gcbb.12205.

URL http://dx.doi.org/10.1111/gcbb.12205

[111] R. E. Sims, W. Mabee, J. N. Saddler, M. Taylor, An overview of second generation biofuel technologies, Bioresource Technology 101 (6) (2010) 1570 - 1580. doi:10.1016/j.biortech.2009.11.046. URL https://doi.org/10.1016/j.biortech.2009.11.046

[112] P. E. Dodds, I. Staffell, A. D. Hawkes, F. Li, P. Grünewald, W. McDowall, P. Ekins, Hydrogen and fuel cell technologies for heating: A review, International Journal of Hydrogen Energy 40 (5) (2015) 2065 2083. doi:10.1016/j.ijhydene.2014.11.059.

URL https ://doi.org/10.1016/j.ijhydene.2014.11.059

[113] R. Lund, B. V. Mathiesen, Large combined heat and power plants in sustainable energy systems, Applied Energy 142 (2015) 389-395. doi : $10.1016 / \mathrm{j}$. apenergy . 2015.01.013.

URL https : //doi.org/10.1016/j. apenergy. 2015.01.013

[114] H. Lund, S. Werner, R. Wiltshire, S. Svendsen, J. E. Thorsen, F. Hvelplund, B. V. Mathiesen, 4th Generation District Heating (4GDH), Energy 68 (2014) 1 -11. doi:10.1016/j . energy. 2014.02.089. URL https : //doi.org/10.1016/j.energy.2014.02.089

[115] M. Pehl, A. Arvesen, F. Humpenöder, A. Popp, E. G. Hertwich, G. Luderer, Understanding future emissions from low-carbon power systems by integration of life-cycle assessment and integrated energy modelling, Nature Energy 2 (2017) 939-945. doi:10.1038/ s41560-017-0032-9.

URL https://doi.org/10.1038/s41560-017-0032-9

[116] M. Z. Jacobson, M. A. Delucchi, Z. A. Bauer, S. C. Goodman, W. E. Chapman, M. A. Cameron, C. Bozonnat, L. Chobadi, H. A. Clonts, P. Enevoldsen, J. R. Erwin, S. N. Fobi, O. K. Goldstrom, E. M. Hennessy, J. Liu, J. Lo, C. B. Meyer, S. B. Morris, K. R. Moy, P. L. O’Neill, I. Petkov, S. Redfern, R. Schucker, M. A. Sontag, J. Wang, E. Weiner, A. S. Yachanin, $100 \%$ Clean and Renewable Wind, Water, and Sunlight All-Sector Energy Roadmaps for 139 Countries of the World, Joule 1 (2017) 1-14. doi:10.1016/j.joule.2017.07.005. URL https : //doi.org/10.1016/j.joule.2017.07.005

[117] D. Schlachtberger, T. Brown, M. Schäfer, S. Schramm, M. Greiner, Cost optimal scenarios of a future highly renewable European electricity system: Exploring the influence of weather data, cost parameters and policy constraints.

URL https : //arxiv.org/abs/1803.09711 